\title{
Assessment of Madden-Julian oscillation simulations with various configurations of CESM
}

\author{
Xiaojing $\mathrm{Li}^{1,2,3} \cdot$ Youmin Tang ${ }^{2,3} \cdot$ Lei Zhou $^{2} \cdot$ Dake Chen $^{2} \cdot$ Zhixiong Yao $^{1,2}$ • \\ Siraj UI Islam ${ }^{3}$
}

Received: 13 July 2015 / Accepted: 15 January 2016 / Published online: 30 January 2016

(C) The Author(s) 2016. This article is published with open access at Springerlink.com

\begin{abstract}
This paper presents an assessment of the Madden-Julian oscillation (MJO) simulated in five experiments using the Community Earth System Model under different model settings. The analysis focused on the effects of air-sea coupling, resolution and atmospheric physics on the basic characteristics of the MJO, including intraseasonal variance, wavenumber-frequency characteristics and eastward propagation, using outgoing longwave radiation (OLR), zonal winds at $850 \mathrm{hPa}$ (U850) and at $200 \mathrm{hPa}$ (U200). Five experiments are conducted for this purpose including one atmospheric model-Community Atmosphere model version 4 (CAM4), two coupled models with CAM4 or Community Atmosphere model version 5 (CAM5) as the atmospheric component at a low resolution (CLP4_2d, CPL5_2d) and two the same coupled model with a high resolution (CPL4_1d and CLP5_1d). The results show that all models have better intraseasonal characteristics in U850 than in OLR. The uncoupled model CAM4 has lower fidelity than the coupled models in characterizing MJO basic features including the temporal and spatial intraseasonal variability and the eastward propagation. With ocean feedback, the coherence of convection and circulation is improved in the coupled models. The higher resolution is helpful in improving ISV spatial distribution
\end{abstract}

Youmin Tang

ytang@unbc.ca

1 College of Ocean and Earth Sciences, Xiamen University, Xiamen, China

2 State Key Laboratory of Satellite Ocean Environment Dynamics, Second Institute of Oceanography, Hangzhou, China

3 Environmental Science and Engineering, University of Northern British Columbia, Prince George, Canada and eliminating low frequency bias in the frequencywavenumber spectra although it has little improvement to MJO-band variance (power) in frequency-wavenumber spectra. The new shallow convection scheme in CAM5 improves the moisture process of the lower troposphere so that CPL5_2d and CPL5_1d have more realistic eastward propagation speed in the boreal winter and better northward propagation in the boreal summer than other models. However, the strength of the convective MJO signal in CPL5_2d and CPL5_1d are weaker than other models and observations, which is probably one of the most spurious features in CPL5_2d and CPL5_1d experiments, suggesting that the CAM5 has a weaker convection activity than its predecessor.

Keywords Madden-Julian oscillation - CESM · Coupled model $\cdot$ MJO simulation diagnostics · Tropical intraseasonal oscillation

\section{Introduction}

The Madden-Julian oscillation (MJO) is the dominant mode of intraseasonal variability (ISV) in the tropics (Madden and Julian 1994). Coherent eastward propagation of convection and zonal wind over the Indian Ocean, the Maritime Continent, and the western Pacific Ocean are the salient features of the MJO. Furthermore, the MJO plays a critical role in connecting the weather and climate variation. Thus, the MJO has become an intensive research topic in recent years. Many studies focused on understanding (e.g., Zhang 2005; Kang et al. 2010; Li 2014) and predicting the MJO using statistical and dynamical methods (e.g., Ding et al. 2010; Kang et al. 2014; Wang et al. 2014). Moreover, the MJO has extensive interactions with other components 
of the climate system, for instance, the El Nino-Southern Oscillation (Tang and Yu 2008a, b; Hoell et al. 2014), the Asian and Australian monsoon systems (Bai et al. 2013; Evans et al. 2014), and the extratropics (Moon et al. 2007; Lin et al. 2010). Therefore, it is important to represent the MJO realistically in models for climate modeling and prediction.

There have been numerous studies on MJO simulations using different models (e.g., Zhang et al. 2006; Kang and Kim 2010; Subramanian et al. 2011; Crueger et al. 2013; Shelly et al. 2014). However, MJO simulation is still a big challenge for the modeling community. Some important issues that affect MJO simulation have been investigated. For example, by analyzing the MJO simulation in the 42 MJO experiments performed with ECHAM6 and previous ECHAM versions, Crueger et al. (2013) confirmed the importance of a better convection scheme and air-sea coupling at high resolution in obtaining a better simulation of the MJO. Shelly et al. (2014) investigated the impact of a fully interactive ocean on hindcast of the MJO, and found that the coupled configuration can extend MJO predictability and that $\mathrm{MJO}$ propagation was also improved in the coupled global circulation model (CGCM).

Among the models used for MJO studies, the National Center for Atmospheric Research (NCAR) Community Earth System Model (CESM) and various versions of its predecessor Community Coupled System Model (CCSM) have played important roles, by which many studies related to MJO simulations and predictions were conducted (e.g., Mu and Zhang 2008; Sperber 2004; Zhang and Mu 2005; Subramanian et al. 2011). For example, Sperber (2004) compared the simulated MJO in the CCSM Version 2 (CCSM2) and the Atmospheric Model Version 2.0 (CAM2), and found that CCSM2 represented the MJO better than CAM2.0 due to the presence of air-sea interaction, although the amplitude and spatial extent of the intraseasonal convection were underestimated compared with observed outgoing longwave radiation (OLR). Zhang and $\mathrm{Mu}$ (2005) presented the MJO simulation in the CCSM3, showing that the amplitudes of the MJO in $850-\mathrm{hP}$ zonal wind (U850), precipitation, and OLR were comparable to those of the observations, and that the MJO had an apparent eastward propagation from the Indian Ocean to the Pacific. However, the period of the MJO was shorter than the reality in their study. Subramanian et al. (2011) explored in detail the MJO simulation in CCSM4 and found that CCSM4 reproduced a number of MJO behavior features more realistically than its predecessors, such as coherent patterns in eastward-propagating intraseasonal zonal winds and OLR over the tropical Indian and Pacific oceans, and the strong peaks with periods between 20 and 100 days and zonal wavenumbers between 1 and 3 in power spectra and coherence spectra. Simulated MJOs, however, tended to be more broad-banded in frequency than the observed. Boyle et al. (2015) explored the ability of CAM5 in simulating MJO by a perturbed parameter ensemble. By modifying five key parameters in the deep convection parameterization, they improved their MJO simulation, including amplitude of the ISV and of low-level moisture and heating anomalies to the east of the convective center.

In order to facilitate the comparison of MJO simulations in different GCMs, the Madden-Julian oscillation Working Group (MJOWG) of US CLIVAR developed a standardized set of diagnostics (Waliser et al. 2009). Using this diagnostic standard, Kim et al. (2009) examined the ability of eight climate models and Subramanian et al. (2011) assessed the MJO simulated by CCSM4. In order to provide an initial indication of MJO performance, a series of metrics was proposed by Sperber and Kim (2012), which can capture the salient features related to the propagation of convection of the MJO.

Of many important issues, the convection scheme, model resolution and the atmosphere-ocean coupling are probably the most influential to the MJO simulation in a climate model. In this study, we evaluate the CESM capability in simulating MJO, including the features that can and cannot be well captured by the CESM. Emphasis is placed on the impacts of model resolution, the atmosphereocean coupling and atmosphere physics on MJO simulation in CESM, in particular, exploring the effects of the new shallow convection scheme of CAM5 on MJO simulation. This shall be a good complement to the MJO simulations by CESM predecessors, which is beneficial to MJO studies. Towards this goal, we conduct five experiments with different resolutions and atmosphere models in CESM to examine and diagnose the MJO simulations. The model version we use was released in December 2013, and composed of individual components simultaneously simulating the Earth's atmosphere, ocean, land, land-, and sea-ice, plus one central coupler.

In Sect. 2, we briefly describe the CESM used, including the difference between two versions of its atmosphere model-Community Atmosphere Model version 4 (CAM4) and version 5 (CAM5), experiment settings, and the observational datasets used for validation. Section 3 presents a detailed MJO diagnostic analysis of these experiments. In Sect. 4, we summarize the results.

\section{Model, experimental setup and data}

CESM is a fully coupled, global climate model that couples the atmosphere, ocean, land, land-ice, and sea-ice. The CESM system can be configured in a number of ways. It supports numerous resolutions and component configurations, and each model component has multiple options to configure specific model physics and parameterizations. 
Table 1 List of the experiments

\begin{tabular}{lllr}
\hline Experiments & Atmosphere physics & Resolution & Description and boundary conditions \\
\hline CAM4_2d & CAM4 & f19_g16 & $\begin{array}{r}1.9^{\circ} \times 2.5^{\circ} \text { grid resolution and 26 vertical levels. Present day climatology (1982-2001) SST } \\
\text { and sea ice datasets }\end{array}$ \\
CPL4_2d & CAM4 & f19_g16 & $\begin{array}{r}1.9^{\circ} \times 2.5^{\circ} \text { grid resolution and 26 vertical levels for CAM4. } 1^{\circ} \times 1^{\circ} \text { grid resolution and } 60 \\
\text { vertical levels for POP. Present day climatology forcing }\end{array}$ \\
CPL4_1d & CAM4 & f09_g16 & $\begin{array}{r}0.9^{\circ} \times 1.25^{\circ} \text { grid resolution and } 26 \text { vertical levels for CAM4. } 1^{\circ} \times 1^{\circ} \text { horizontal resolution and } \\
60 \text { vertical levels for POP. Present day climatology forcing }\end{array}$ \\
& & f19_g16 & $\begin{array}{r}1.9^{\circ} \times 2.5^{\circ} \text { grid resolution and } 30 \text { vertical levels for CAM5. } 1^{\circ} \times 1^{\circ} \text { grid resolution and } 60 \\
\text { vertical levels for POP. Present day climatology forcing }\end{array}$ \\
CPL5_2d & CAM5 & f09_g16 & $\begin{array}{c}0.9^{\circ} \times 1.25^{\circ} \text { grid resolution and } 30 \text { vertical levels for CAM5. } 1^{\circ} \times 1^{\circ} \text { grid resolution and } 60 \\
\text { vertical levels for POP. Present day climatology forcing }\end{array}$ \\
\hline
\end{tabular}

Both CAM4 and CAM5 are available in CESM. The physics in CAM4 have been described in detail by Neale et al. (2010b). For CAM4, the major change over its predecessors is an enhancement parameterization of deep convection in moist physics. An entraining plume assumption is introduced to decrease convection sensitivity to the tropospheric moisture. Moreover, the addition of sub-grid scale convective momentum transport (CMT) results in improvement of the Hadley circulation during the boreal winter, reducing many of the model biases (Zhang and Mcfarlane 1995; Neale et al. 2008). CAM5 only keeps the deep convection parameterization (Neale et al. 2010a), and substantial modification is made with a range of enhancements and improvements in the representation of physical processes over CAM4. CAM5 contains an updated moist boundary layer and shallow cumulus convection scheme that accurately simulates the spatial distribution of shallow convective activity (Park and Bretherton 2009). It is believed that the convection scheme plays a critical role on the eastward propagation of MJO (Zhang and Song 2009; Cai et al. 2013), and much effort has been made to examine the influences of different convection schemes on the MJO simulation. The shallow convection scheme of CAM5 does not have limitation on the cloud top height and convective precipitation, and can compute convective updraft vertical velocity and fractional area which enables to compute more refined fractional entrainment-detrainment rates, cloud top height and penetrative entrainment. The new two-moment stratiform cloud microphysics scheme (Morrison and Gettelman 2008; Gettelman et al. 2010) includes aerosol activation of cloud drops/crystals for liquid and ice, and explicit treatment of aerosol-cloud interaction. The new radiation scheme, the Rapid Radiative Transfer Model for GCMs, is a correlated$\mathrm{k}$ method that has a better performance compared to the line-by-line calculations in CAM4 (Iacono et al. 2008). The revised cloud macrophysics scheme provides a more transparent treatment of cloud processes and imposes a pseudo condensation-evaporation process to remove the inconsistency between stratus fraction and in-stratus cloud condensate
(Neale et al. 2010a). The aerosol treatment in the model uses a modal-based prognostic scheme similar to that in Easter et al. (2004), but with only three modes (Aitken, accumulation and coarse) (Liu et al. 2012), whereas CAM4 uses a prescribed mass-based scheme with direct radiative effects and has no interaction with clouds.

For model resolution, we use two experiments with a resolution of $1.9^{\circ} \times 2.5^{\circ}$ against a resolution of $0.9^{\circ} \times 1.25^{\circ}$. The commonly-seen resolution for some climate models including reanalysis products is $2.5^{\circ} \times 2.5^{\circ}$, such as NCEP I/II and ERA-40. Meanwhile, it has the capability to capture the planetary waves, which have a wavelength on the order of $1000 \mathrm{~km}$. The experiments with the resolution of $1.9^{\circ} \times 2.5^{\circ}$ are representative of commonly-seen climate models. In comparison, the experiments with the resolution of $0.9^{\circ} \times 1.25^{\circ}$ are supposed to have a better capability in capturing synoptic processes (such as, but not limited to, the convectively coupled equatorial waves; Kiladis et al. 2009), which may facilitate a better MJO simulation. For atmosphere-ocean coupling, the atmosphere-only model and the coupled model are compared to shed light on the influences of air-sea coupling on MJO simulation. In addition, the impacts of CAM4 and CAM5 on MJO simulation are also compared, which is to show the improvement of MJO simulation along with the development of atmosphere model, especially by the new shallow convection scheme.

In summary, five experiments are conducted in this study, as listed in Table 1. For instance, Case CAM4_2d means that the model component is a CAM stand-alone model with CAM4 atmosphere physics, and the resolution is $1.9^{\circ} \times 2.5^{\circ}$ finite volume grid for the atmosphere and $1^{\circ} \times 1^{\circ}$ Greenland Pole grid for the ocean (f19_g16 for abbreviation). The stand-alone configuration uses climatological prescribed sea surface temperatures (SSTs) and sea-ice fraction data (Hurrell et al. 2008), which has a horizontal resolution of $1^{\circ} \times 1^{\circ}$. All experiments are integrated for 50 years. Outputs for the last 20 years are used for MJO diagnostics. This way, the impact of the model's spin-up on analysis is avoided. 
Various observations are used to validate the MJO simulation in CESM, including OLR from the advanced very high resolution radiometer (AVHRR) estimate (Liebmann and Smith 1996), specific humidity (SH) daily data from the National Centers for Environmental Prediction (NCEP) reanalysis (Kalnay et al. 1996), zonal winds in the upper (200-hPa) and lower $(850-\mathrm{hPa})$ troposphere obtained from NCEP reanalysis 2 (Kanamitsu et al. 2002). All of these datasets have a horizontal resolution of $2.5^{\circ} \times 2.5^{\circ}$, and we use the data time period from 1981 to 2000 .

\section{MJO diagnostic results}

In this section, we follow the two-level diagnostic strategy proposed by the MJO Working Group to explore model's capability in simulating MJO variability (Waliser et al. 2009). For both level-1 and level-2 diagnostics, the MJO signal is extracted from the observation and model simulation by employing an intraseasonal (20-100 days) bandpass Lanczos filter on the normalized data that has daily climatological mean removed already (Duchon 1979). We choose OLR to characterize convective activity in following analysis.

\subsection{Simulation of intraseasonal variability (ISV) characteristics}

First, level-1 diagnostic is applied to analyze the basic characteristics of the MJO, including the dominant temporal and spatial characteristics, as well as the signal propagations, in OLR and U850.

\subsubsection{ISV spatial distribution}

To examine the model's capability in simulating ISV strength and spatial distribution, we calculate the variance of intraseasonal U850 and OLR, using a band-pass filter of 20-100 days, for boreal winter (Fig. 1) and boreal summer (Fig. 2), respectively. In the boreal winter, the observed U850 shows strong ISV in the south of the Maritime Continent, the western Pacific and the central tropical Pacific whereas the strong ISV occurs in the eastern Indian Ocean, south of the Maritime Continent, and the western Pacific in observed OLR. The uncoupled model experiment CAM4_2d shows unrealistic ISV spatial pattern in both U850 and OLR fields. For example, the U850 has strong ISV in the eastern central Indian Ocean which is absent in the observation, whereas the OLR has much stronger ISV in the simulation than in the observation for almost all regions. On the other hand, the basic spatial distribution pattern of ISV is better represented in all coupled model experiments as indicated by the spatial correlation and the root-mean-square-error (RMSE) shown at the upper-right of each figure panel. All experiments show that the simulated variance magnitude has some differences from that of the observations, especially in the OLR. Compared with the observations, the CPL4_1d has the smallest RMSE for U850, while the best pattern correlation occurs in CPL5_1d. For OLR, the smallest RMSE is shown in CPL5_1d experiment, while CPL4_1d gives the best pattern correlation.

In the boreal summer, the locations of maximum ISV variance in both observed U850 and OLR move northward, which can be represented by all model experiments. However, there are still some biases in magnitude and spatial distribution of MJO variance in the experiments with CAM4 physics, compared to the observations, such as unrealistically high variance in the northwest Indian Ocean for U850 and in the east of warm pool of Pacific Ocean for OLR. The ISVs of the OLR are overestimated in all model experiments as in the boreal winter. In addition, both pattern correlation and RMSE of U850 and OLR fields are consistent with those in the boreal winter, namely, CPL4_1d and CPL5_1d have comparable performance and better than other models.

\subsubsection{Frequency-wavenumber ISV characteristics}

Wavenumber-frequency spectrum can capture the MJO's intraseasonal characteristic and eastward propagation dominance. Since MJO signal is usually strongest in boreal winter, the analysis here is confined in this period. Figures 3 and 4 shows, respectively, the wavenumber-frequency spectra for the equatorial OLR and U850 anomaly in the boreal winter, using the method described in Wheeler and Kiladis (1999). The value of R, defined by the ratio of eastward-propagating and the westward-propagating component power of the intraseasonal band, is calculated for both observations and model outputs.

The observed spectrum values are large at zonal wavenumbers 1-3 for OLR and at wavenumber 1 for U850 at the period of 30-90 days, which is consistent with previous results (Zhang et al. 2006; Waliser et al. 2009). In CAM4_2d, OLR anomaly shows large westward power (to the left of the zero frequency) occurring at high wavenumbers 3 and 4, in contrast with the large eastward power (to the right of the zero frequency) occurring at wavenumber 1 . The value of $\mathrm{R}$ is $>1$, indicating that the eastward propagation, at the period range of 30-80 days, is more dominant. CPL4_2d seems better than CAM4_2d in capturing dominant propagation direction and intraseasonal signals in the power spectra, but an extremely high power appears at about 200-day period in both eastward and westward propagation, which is unrealistic. This bias in low frequency is also presented in the analysis of precipitation in uncoupled 


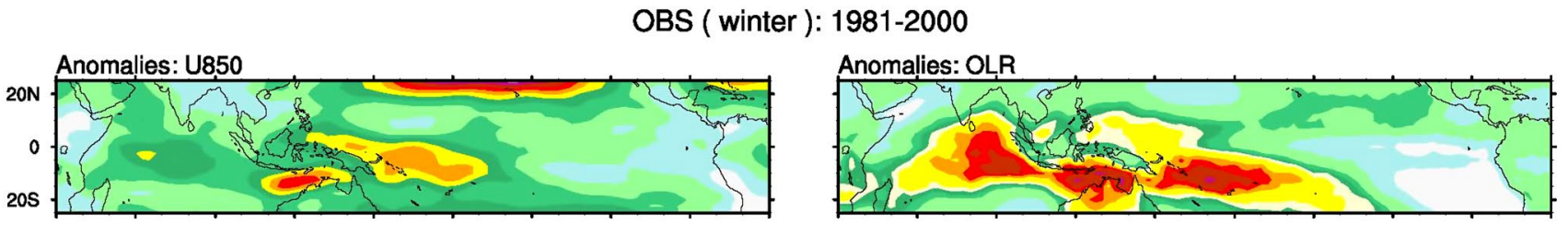

CAM4_2d (winter)
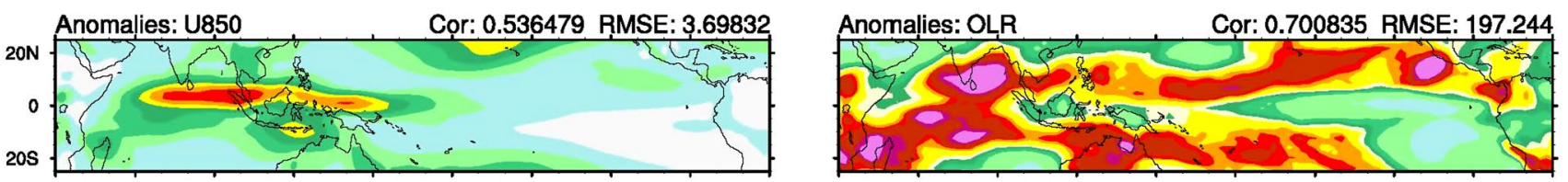

CPL4_2d (winter)
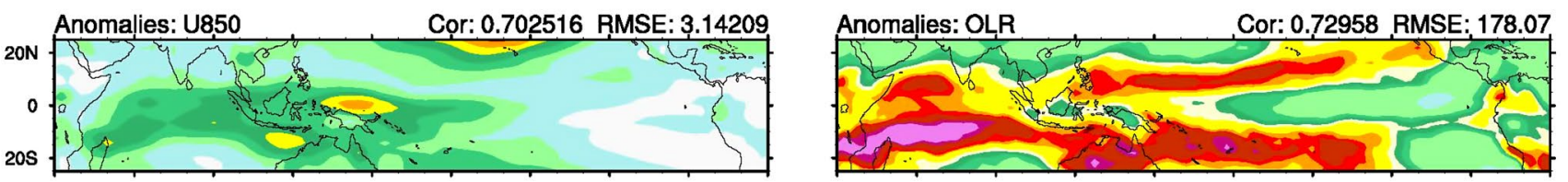

CPL4_1d ( winter)
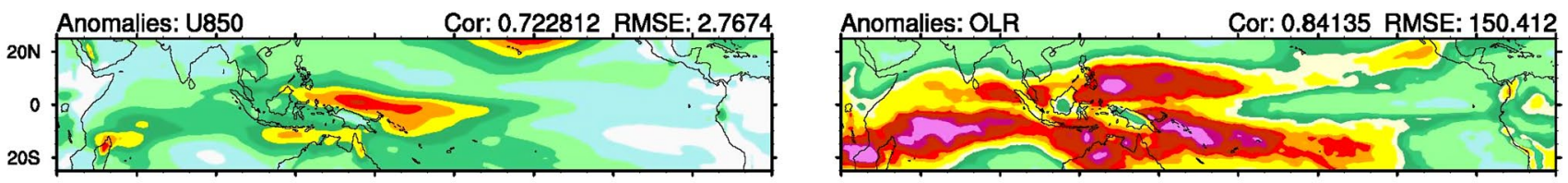

\section{CPL5_2d (winter)}
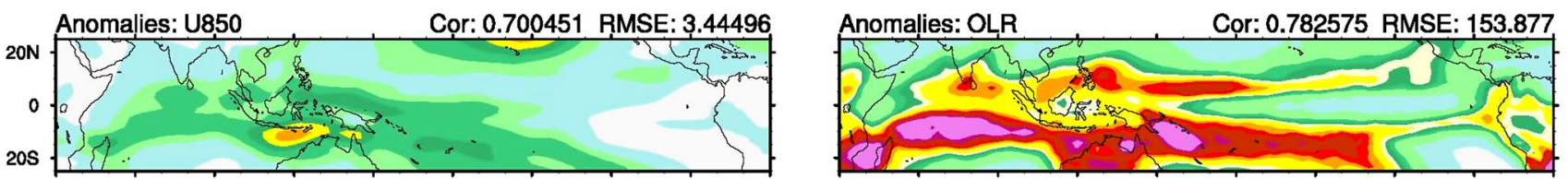

CPL5_1d ( winter)

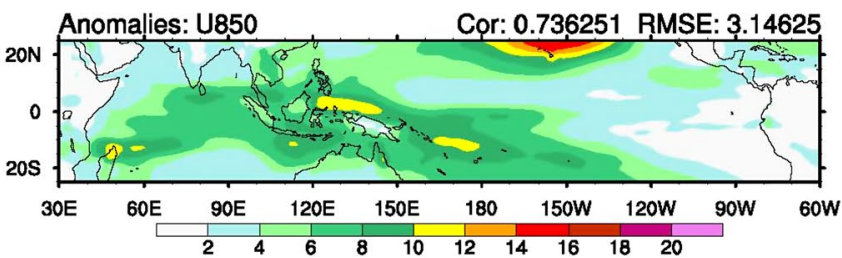

Fig. 1 ISV variances of U850 (left) and OLR (right) during the boreal winter from observations and various model simulations. The ISV is obtained using a 20-100 day band-pass filter applied to daily

model CAM5 by Boyle et al. (2015). When the model resolution is improved, this bias disappears although the peak of period is discontinued at 35 days as shown in Fig. 3. CPL5_2d also shows a high eastward propagation power at the period of 200 days and at wavenumber 2 and 3 as CPL4_2d, which is not consistent with the realistic MJO frequency and wavenumber band. However, the high resolution cannot help to increase the power in the MJO band, as shown in Fig. 3 for CPL5_1d case, although the bias at

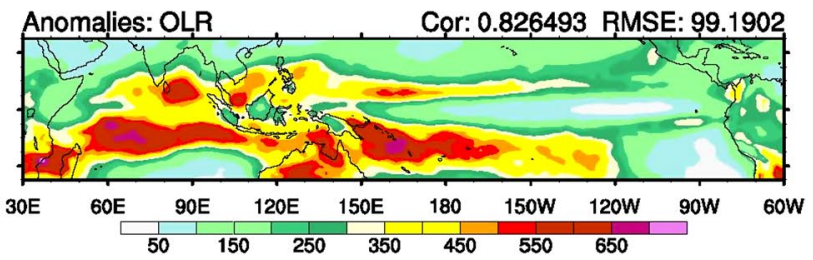

data. The pattern correlation and RMSE against the observations are labelled at the upper-right corner of each panel

the period of 200 days is eliminated. Therefore, experiments with CAM5 are poor in representing the ISV features of MJO in the frequency-wavenumber spectra.

The U850 field shows more realistic ISV features than the OLR field analyzed above in the frequency-wavenumber spectra for both uncoupled and coupled model experiments, when compared with the observations. The R of U850 is relatively higher than that of OLR in the coupled experiments, which indicates eastward 


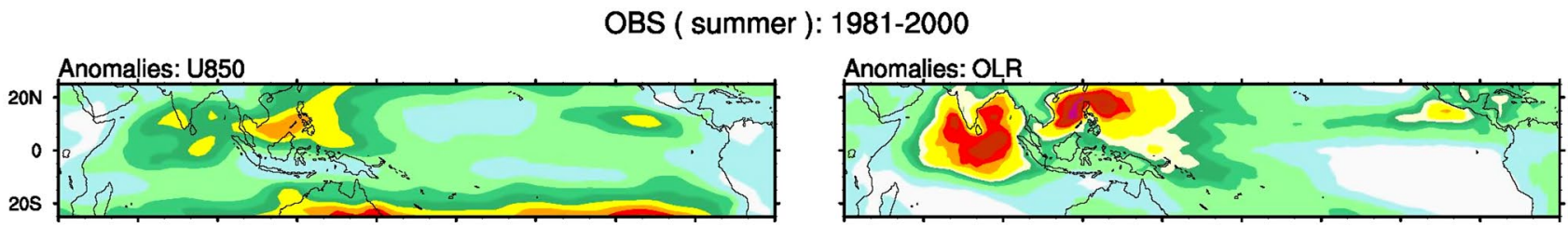

CAM4_2d (summer)
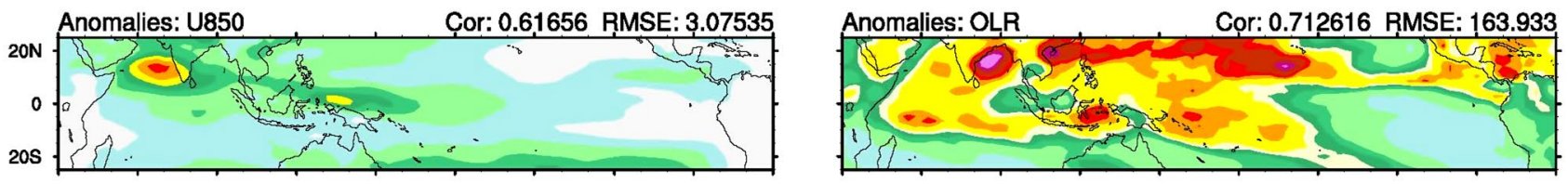

CPL4_2d (summer)
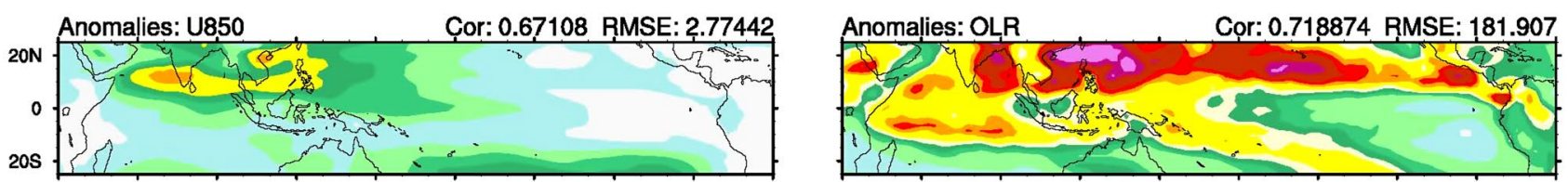

CPL4_1d ( summer)
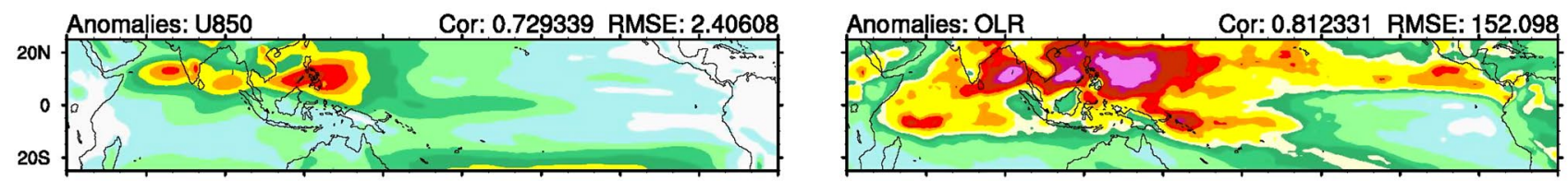

CPL5_2d ( summer)
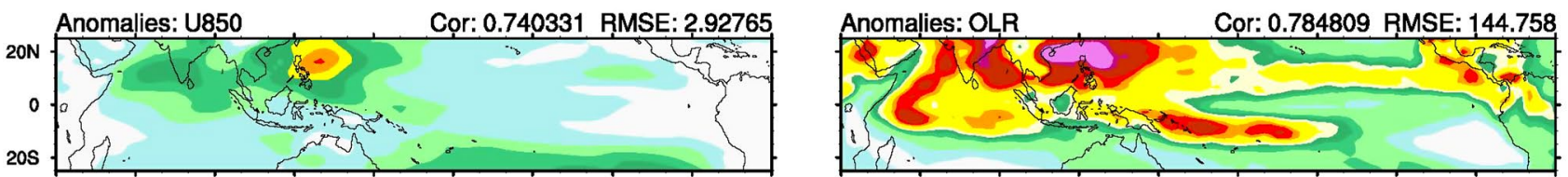

CPL5_1d (summer)
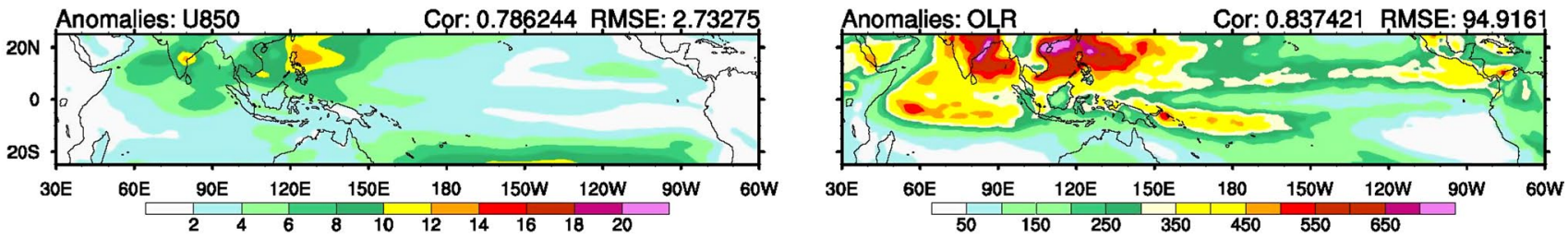

Fig. 2 Same as Fig. 1, except during the boreal summer

propagation of large-scale circulation more dominant than convection. All experiments show a large eastward power at wavenumber 1 as the observations. However, there are some biases for the frequency range of MJO. Compared with observation, CAM4_2d shows much weaker eastward power, while coupled experiments with coarse resolution present larger power in the lower frequency. Relatively, CPL4_1d and CPL5_1d have the most comparable $\mathrm{R}$ values and frequency range of MJO with the observations.

\subsubsection{Eastward and northward propagations}

The eastward propagation is one of the distinct characteristics of the MJO. In addition, the MJO also shows northward propagation in the boreal summer (e.g., KemballCook and Wang 2001; Sharmila et al. 2013). To extract the fundamental propagating and time-varying characteristics of the MJO, we calculate point-to-point correlation using the average intraseasonal OLR anomalies over the area of $10^{\circ} \mathrm{S}-5^{\circ} \mathrm{N}$ and $75^{\circ} \mathrm{E}-100^{\circ} \mathrm{E}$ as a reference, where the 

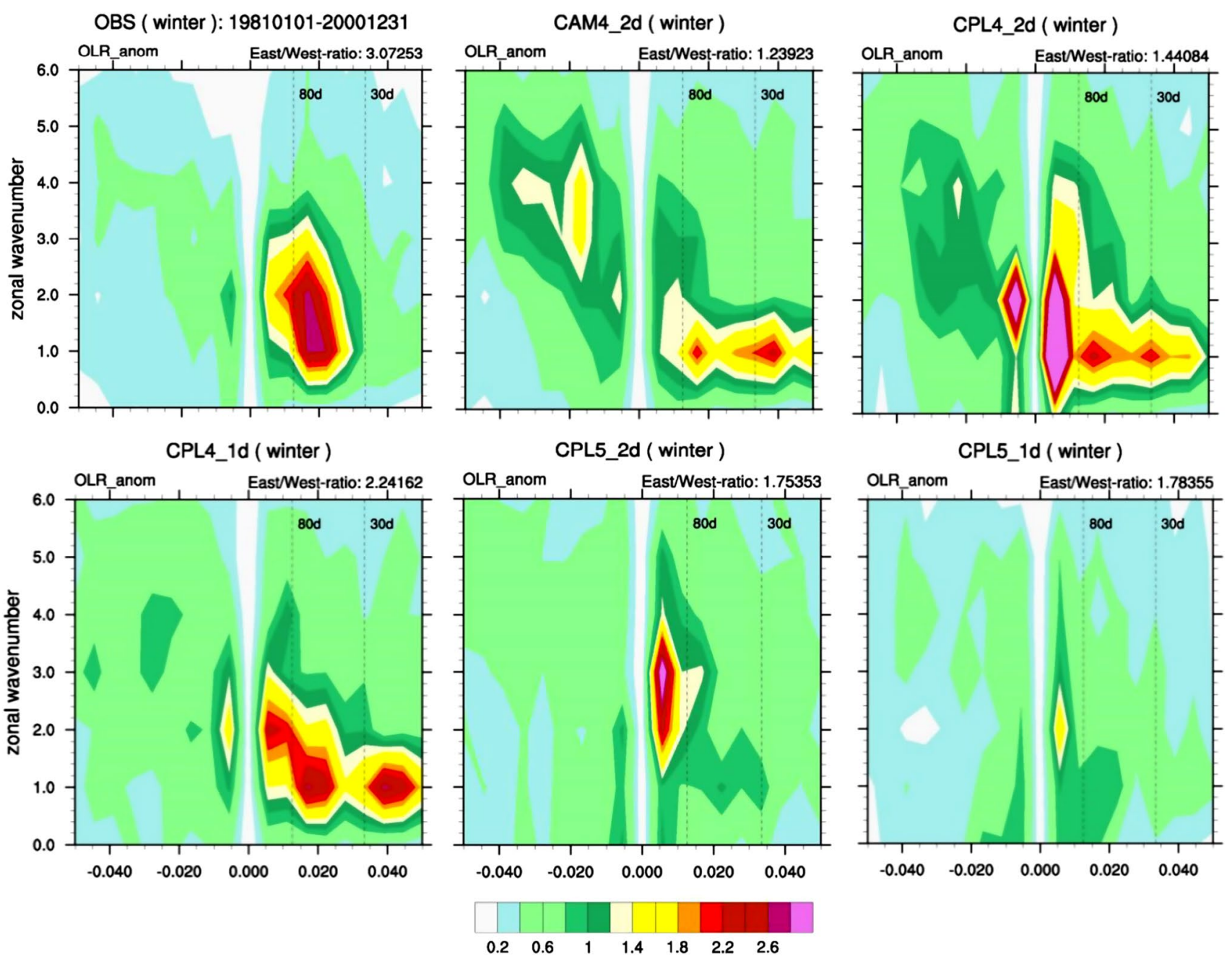

Fig. 3 Wavenumber-frequency spectra of OLR anomaly of each experiment averaged over $10^{\circ} \mathrm{S}-10^{\circ} \mathrm{N}$. The ratio of eastward spectral power to westward spectral power in the MJO band is labeled at the right above each panel. Individual spectra were calculated for each year and then averaged over 20 years. Only the climatological seasonal cycle and time mean for each boreal winter segment were removed before the calculation standard deviation (SD) of intraseasonal OLR reaches the maximum. Shown in Fig. 5 is the time-lag-longitude diagram of the point-to-point correlation for the OLR (shading) and U850 (contour) between $10^{\circ} \mathrm{N}$ and $10^{\circ} \mathrm{S}$-averaged OLR/U850 and the reference in the boreal winter. Similar to Fig. 5, Fig. 6 is the time-lag-latitude diagram of pointto-point correlation for the OLR (shading) and U850 (contour) between $80^{\circ} \mathrm{E}$ and $100^{\circ} \mathrm{E}$-averaged OLR/U850 and the reference in the boreal summer. The main observed features in Fig. 5 can be summarized as follows: (1) there is an obvious eastward propagation over the Eastern Hemisphere (EH) in both OLR and U850; (2) the eastward propagation in OLR is confined to the EH and the U850's phase speed is about $5 \mathrm{~m} / \mathrm{s}$ as that of OLR in the $\mathrm{EH}$, but accelerates east of the dateline; and (3) the lag of the westerly wind anomaly is about 5-7 days behind the negative OLR anomaly in the EH. Comparison among model outputs reveals that none of the model experiments reproduces these observed features very well. For OLR, experiments CAM4_2d and CPL4_2d seem much more like a standing oscillation with a pronounced westward propagation in the U850. CPL4_1d appears to show a better eastward propagation in both OLR and U850, although the phase speed is a little faster than the observation. CPL5_2d and CPL5_1d show effective improvements in simulating the eastward propagation phase speed in the EH, in particular for CPL5_1d, which is comparable to the observations. In CPL5_1d, the simulation shows a similar spatial pattern to the observations; for example, there is a realistic speed change across the dateline in U850.

For the boreal summer, Fig. 6 shows a distinct northward propagation with the phase speed of about $1.2 \mathrm{~m} / \mathrm{s}$ in 

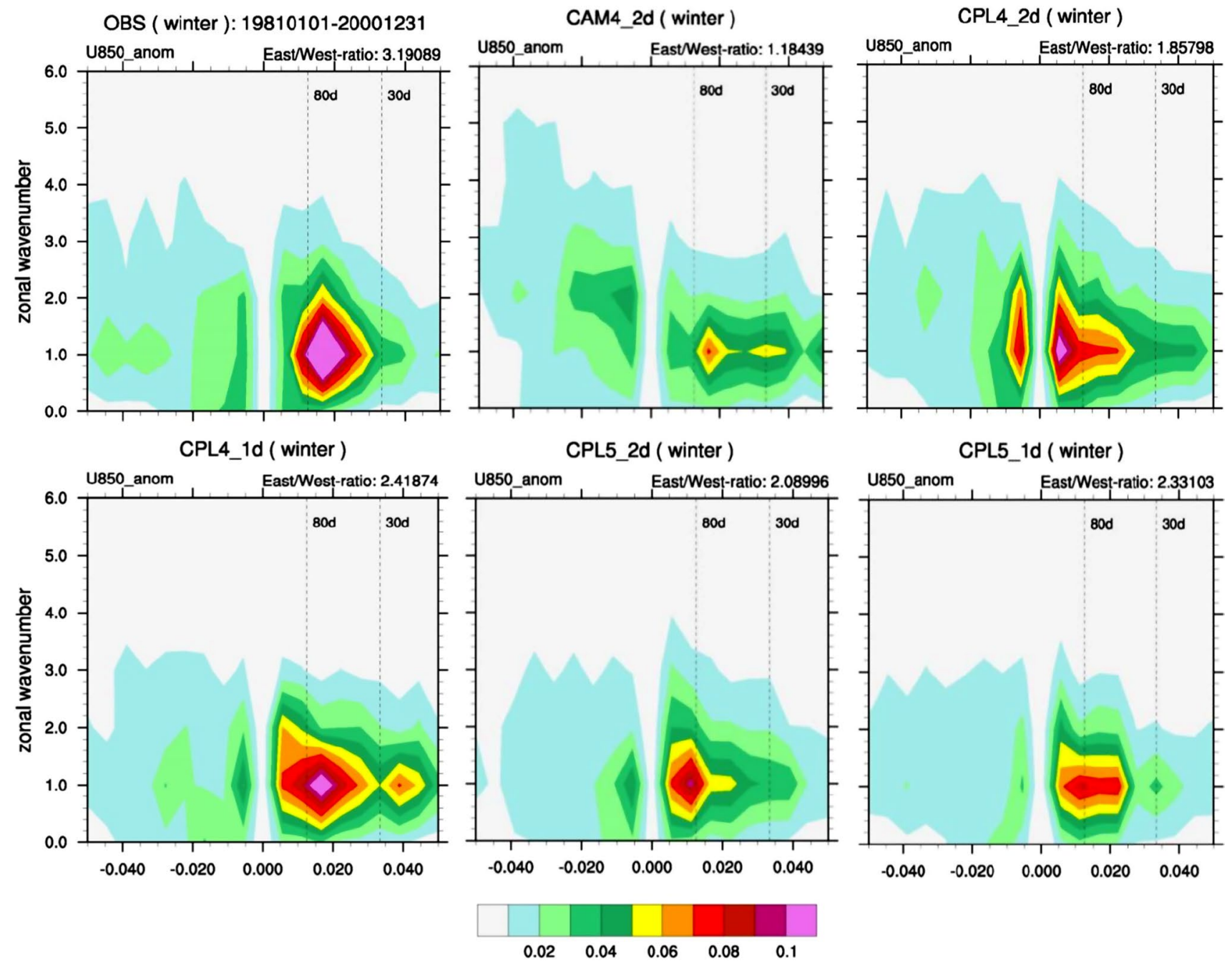

observed OLR and U850. However, the northward propagation is not well simulated in the models. Relatively, the two CPL5 experiments have slightly better performances than CAM4 and CPL4 experiments.

It is interesting to insight some possible dynamic processes behind these model experiments. For the uncoupled experiment (CAM4_2d), the coupling between Rossby waves and Kelvin waves in the atmosphere is likely to be weakened due to the lack of the oceanic feedback that is important to their coupling (e.g., Wang and Rui 1990). As a result, both Kelvin waves and Rossby waves develop separately in response to a heat source over the tropical Indian Ocean. In the coupled model, when the resolution is low (CPL4_2d and CPL5_2d), the subtle phase difference between the dynamic fields and the thermodynamic field may not be well resolved. Thus, although oceanic feedback is allowed, the selection of eastward-propagating Kelvin component over the westward-propagating Rossby wave component is not captured well. When the resolution is increased to $1^{\circ}$ (CPL4_1d and CPL5_1d), the heating center slightly moves to the westerly wind, which enables energy accumulation and leads to wave instabilities. In short, the above lag-longitude and lag-latitude analyses reveal that the air-sea interaction and model resolution are both important for simulating the eastward propagation in the boreal winter, while the northward propagation in the boreal summer seem to be more sensitive to the atmosphere model (Sharmila et al. 2013). This may suggest that the eastward propagation and northward propagation would have different mechanisms.

\subsection{Coherence of simulated MJO}

After assessing the MJO general characteristics, we will conduct level-2 diagnostics to further explore MJO features and properties, especially in a coherent framework of joint variables by using multivariate combined $\mathrm{EOF}$ analysis. 

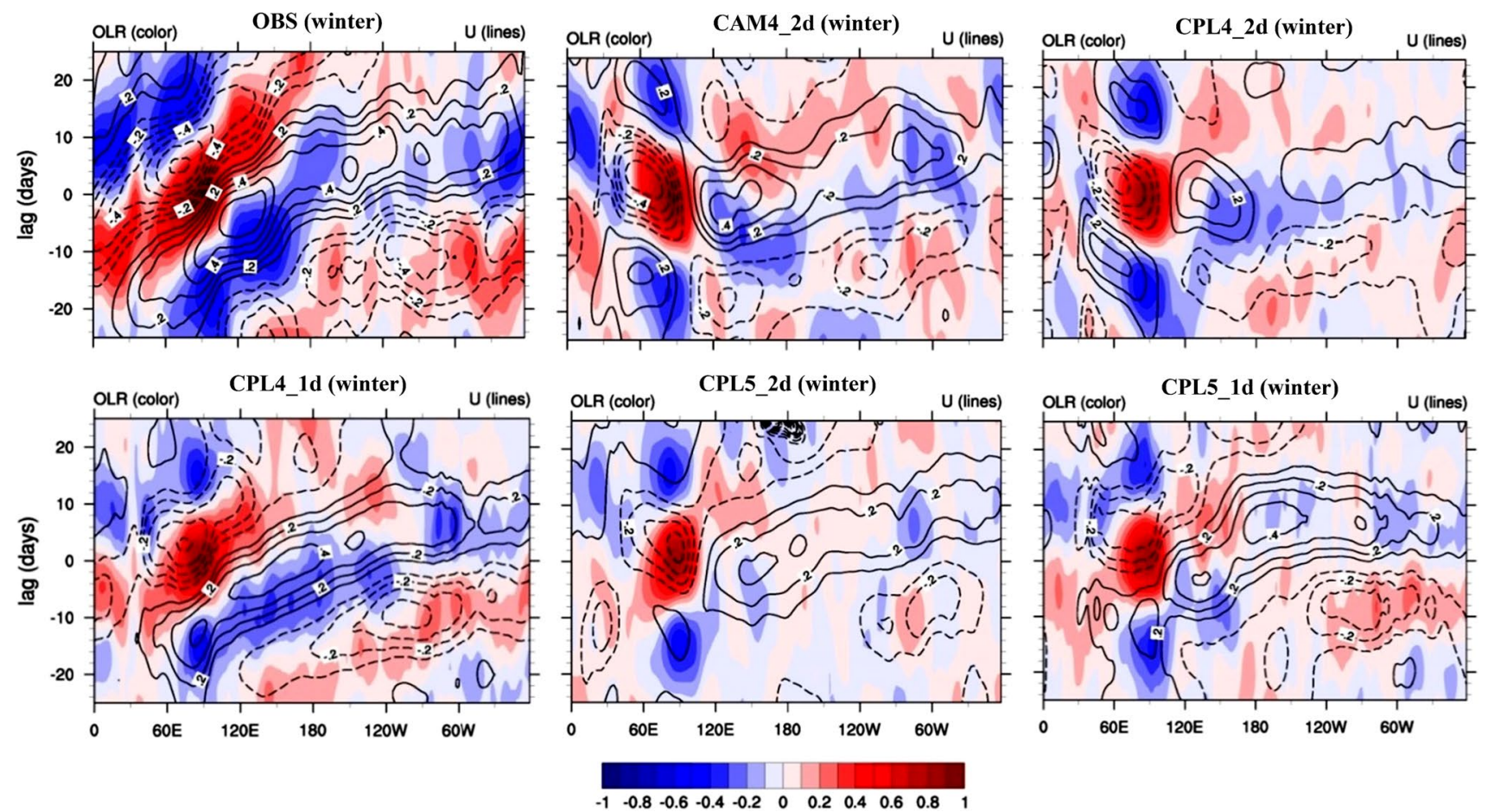

Fig. 5 Lag-longitude diagram of $10^{\circ} \mathrm{N}-10^{\circ} \mathrm{S}$-averaged OLR (shading) and U850 (contoured) correlated against intraseasonal OLR anomaly averaged over the reference region $\left(10^{\circ} \mathrm{S}-5^{\circ} \mathrm{N}, 75^{\circ} \mathrm{E}-100^{\circ} \mathrm{E}\right)$ for the boreal winter for observations and simulations
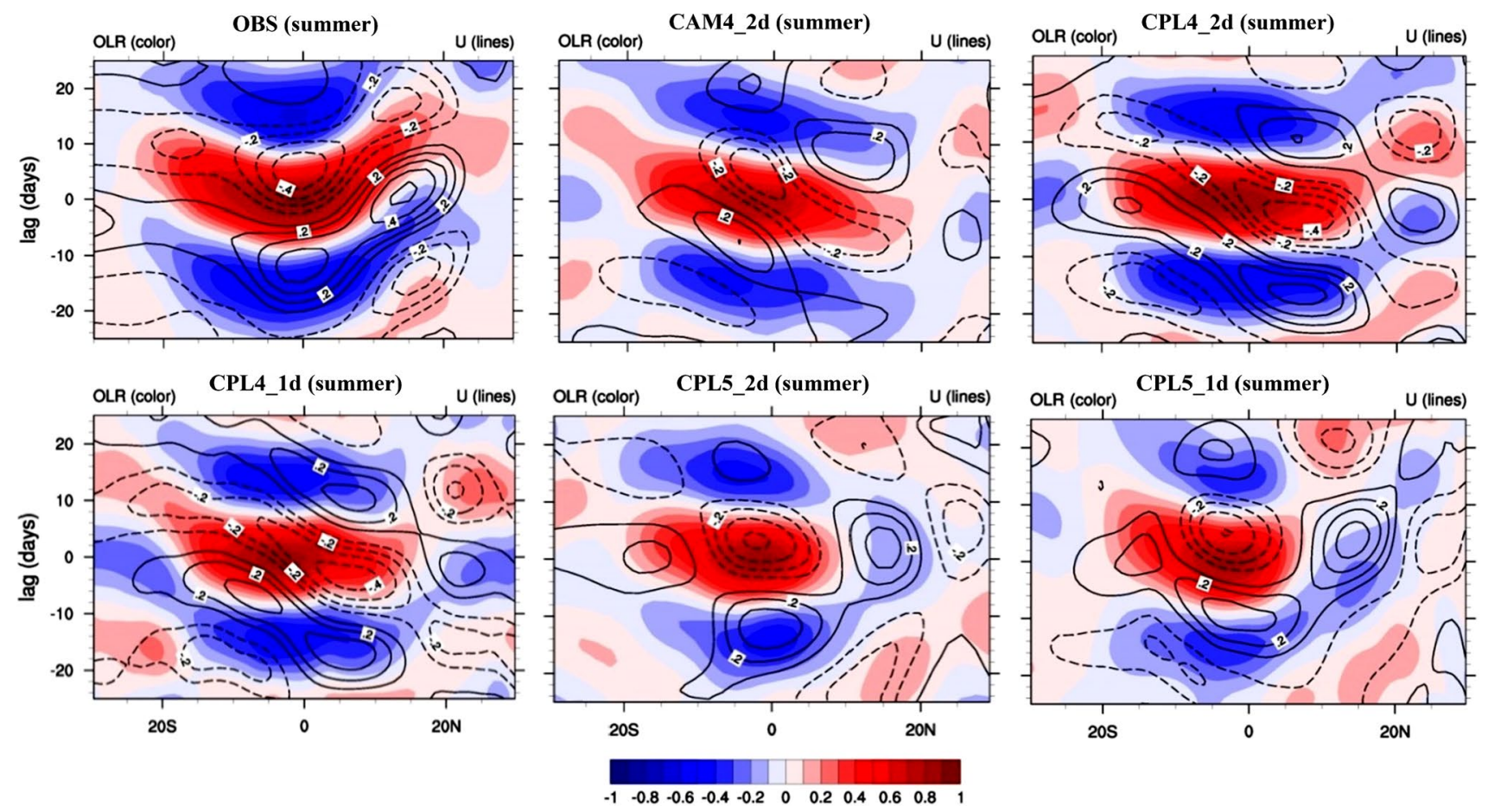

Fig. 6 Similar to Fig. 5, except for the lag-latitude diagram for OLR (shading) and wind (contoured) averaged over $80^{\circ} \mathrm{E}-100^{\circ} \mathrm{E}$ during boreal summer for observations and simulations 


\subsubsection{Cross spectra of U850 and OLR}

Figure 7 shows the coherence squared and the phase spectra between the equatorial OLR and U850. To examine the details in the MJO band, the partially enlarged view of the symmetric and asymmetric part is also shown. Observations exhibit a high degree of coherence and an approximate $90^{\circ}$ phase lag ( $1 / 4$ cycle) between OLR and U850 at zonal wavenumbers $1-3$ and the 30-80 day band for the symmetric component. It is argued that, the signal of the wavenumber 1 and 30-80 day period may be linear convectively coupled Kelvin wave (e.g., Hendon and Wheeler 2008). The corresponding asymmetric part in the MJO band, which should have no imprint of a linear Kelvin wave, helps us to distinguish the MJO signal from high frequency convectively coupled Kelvin waves. For instance, the asymmetric part of observations reveals significant coherency (0.15-0.35) at wavenumber 1 and the 30-80 day band, indicating that the high coherency at wave number 1 is significant MJO behavior other than Kelvin waves.

All model experiments show a significant coherency in the MJO band of the symmetric part, with a phase lag similar to the observation. However, for wavenumber 1 , CAM4_2d and CPL4 have coherency peaks at higher frequencies near 30 days, compared to that near 40 days in the observation. This fact suggests that the models should have more linear convectively coupled Kelvin wave activity than the observation (e.g., Roundy 2008). In the asymmetric part, CAM4_2d has a significant coherency (0.050.20 ) for wavenumber 1 in the 30-80 day band, somewhat weaker than that in the observation. The CPL4_2d has a significant coherency $(0.05-0.20)$ only at around the period of 80 days, while CPL4_1d has a significant coherency at both 30- and 80-day period. CPL5_2d shows the same characters as CPL4_2d, except for slightly stronger coherency $(0.10-0.25)$ of MJO band in asymmetric part. CPL5_1d has significant coherency $(0.10-0.25)$ for wavenumber 1 in the 30-80 day band as the asymmetric component in the observation. These asymmetric structures suggest that the convectively coupled activity at wavenumber 1 , simulated by different model experiments, tends to have more Kelvin waves activity than observation. At wavenumbers 2 and 3, all of the experiments have lower coherency in the MJO band than observation. Instead, these experiments all show high coherency for these two wavenumbers at 10-20 day periods, which indicates Kelvin-like convectively, coupled waves with the coherence falling along the linear Kelvin dispersion curve. This is supported by the fact that the corresponding asymmetric part has no significant coherency at the two wavenumbers at 10-20 day periods. This may be associated with a lack of coupling between MJO and oceanic Kelvin waves in the central equatorial Pacific (e.g., Roundy and Kravitz 2009). Furthermore, it should be noticed that in both CPL5_2d and CPL5_1d there is a strong power for wavenumber 2 around 200-day period, which is also consistent with the results shown in Sect. 3.1.2. The coherent power of the convectively coupled Kevin wave signal is much larger in the two models than in the observations suggesting an overestimation of the convectively coupled Kevin wave signal power in the model simulations.

\subsubsection{EOF analysis}

3.2.2.1 EOF analysis for the OLR The empirical orthogonal function (EOF), also called principal component analysis (PCA), is widely applied to atmospheric variables that characterize the tropical convection activity to extract basic features of the MJO. Figure 8 is the first two leading EOFs of observed OLR in the boreal winter, derived from a 20 to 100 day band-pass-filtered daily OLR data, showing a large convection cell dominating over the equatorial eastern Indian Ocean and the western Pacific. The winter season is chosen because MJO usually has the strongest signals in this season.

The lead-lag correlation between the first two principal components (i.e., PC1 and PC2) is used as a simplified metrics, which was originally proposed by Sperber and Kim (2012), to access model simulation capability of MJO features. Generally, the amplitude of the maximum positive correlation measures how coherent and/or dominant the propagation is, whereas the corresponding time lag indicates the transition time taken from EOF2 to EOF1. A positive (negative) lag indicates PC2 leading (lagging) PC1, suggesting the eastward (westward) propagation of enhanced convection from the Indian Ocean (Maritime Continent) to the Maritime Continent (Indian Ocean).

Shown in Fig. 9 are the lead-lag correlations between PC1 and PC2 for observations and for simulations, respectively, where the model PCs are obtained by projecting simulated 20-100 day band-pass-filtered daily OLR onto the two leading EOFs of observed MJO as shown in Fig. 8. As can be seen in Fig. 9, the observed PC1 and PC2 have a maximum positive correlation of 0.71 at a time lag of about 10 days. All simulations reach the maximum positive correlation at similar time lag of 10-11 days, and the correlation coefficients are generally smaller than observed counterpart, indicating that the eastward propagation of simulated MJO is not as obvious as observed. In addition, the correlation structure of each experiment is somewhat different from that of the observations in Fig. 9. For example, the uncoupled experiment CAM4_2d displays the correlation interchanging the sign more often than that of the observations. CPL4_2d eliminates the spurious structure (with two positive peaks), whereas CPL4_1d shows a larger positive correlation at positive time lag. Both CPL5_1d and CPL5_2d 

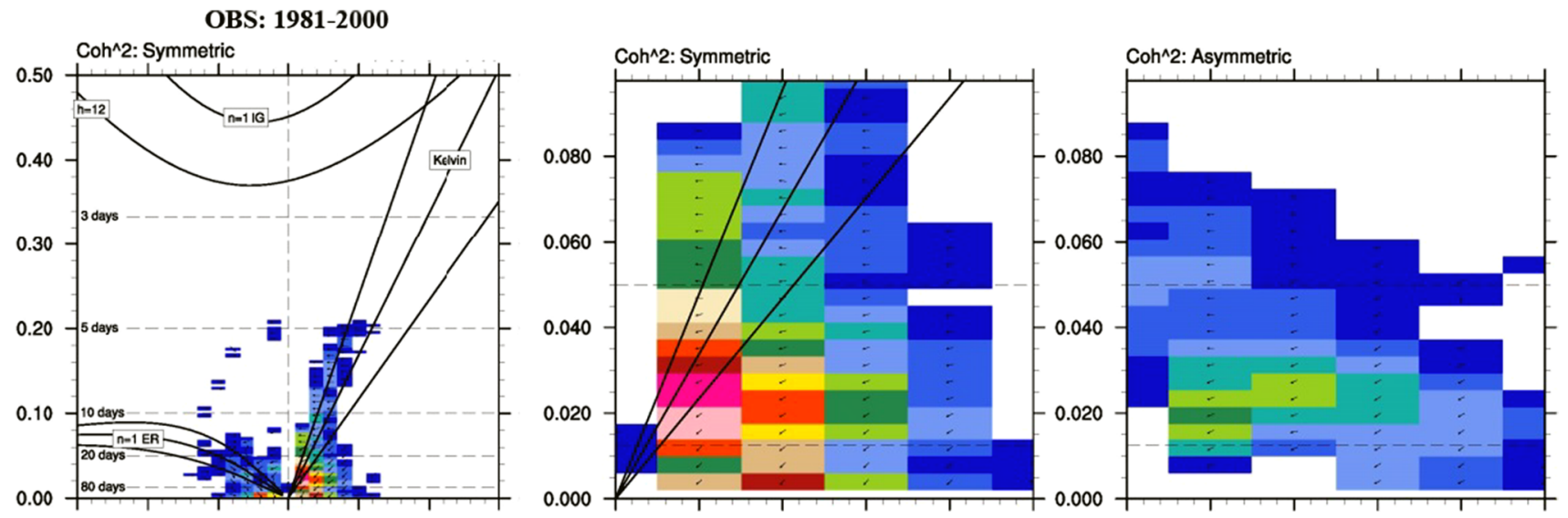

CAM4_2d
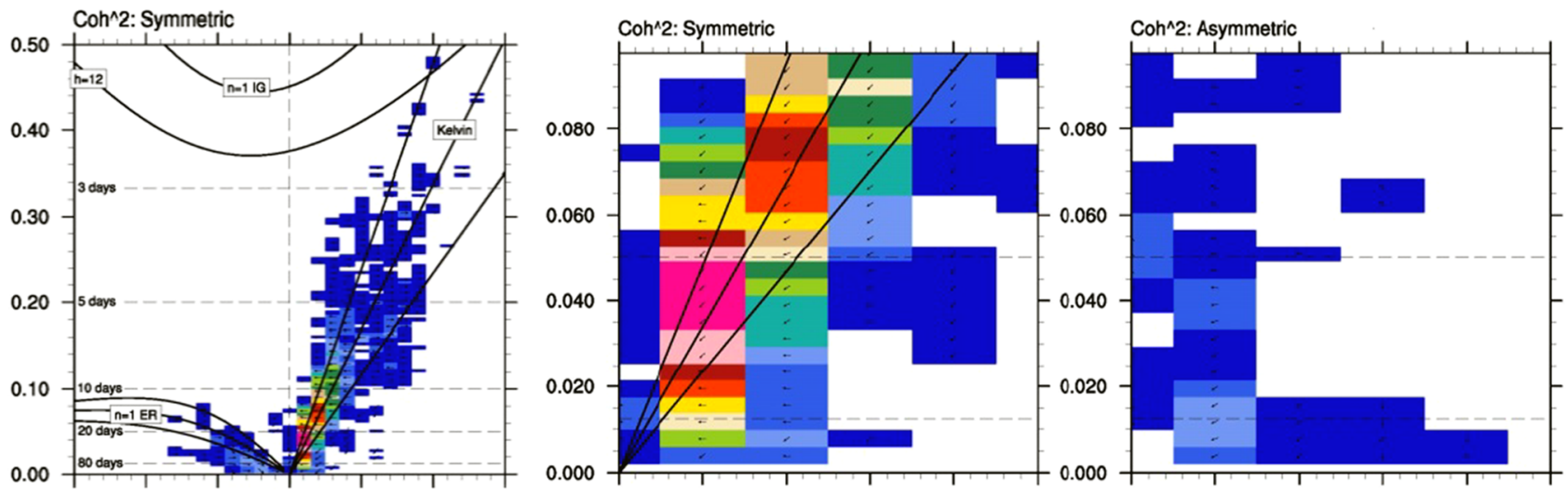

CPL4_2d
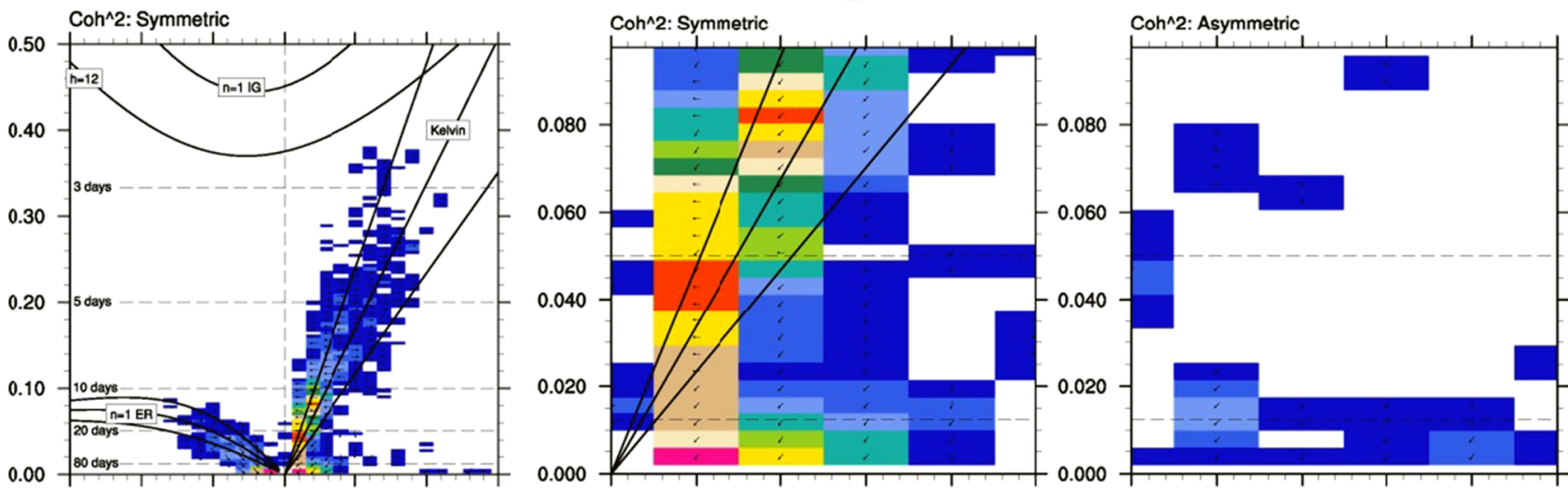

CPL4_1d

Fig. 7 The symmetric part (first column and second column in details in the MJO band) and asymmetric part (third column in the MJO band) of the coherence squared (colors) and phase lag (vectors) between U850 and OLR. Spectra were computed for individual latitudes, and then averaged over $0^{\circ}-10^{\circ}$. Cross spectra were calculated using daily data during all seasons on 256-day-long segments, with consecutive segments overlapping by 206 days. Colors represent coherence squared between OLR and U850, and vectors represent the

show similar features to the observations with CPL5_1d being better in simulating MJO signal strength, as indicated by its larger maximum correlation than that of CPL5_2d. phase by which wind anomalies lag OLR anomalies, increasing in the clockwise direction. A phase of $0^{\circ}$ is represented by a vector directed upward. Dispersion curves for the $(n=-1)$ Kelvin $(n=1)$ equatorial Rossby and $(n=1)$ inertia-gravity waves corresponding to three equivalent depths $(\mathrm{h}=12,25$ and $50 \mathrm{~m})$ in the shallow-water equations are overlaid (black contours). The MJO is defined as the spectral components within zonal wavenumbers $1-3$ and having periods of 30-80 days

In short, the simplified metrics indicates that all simulations can capture the eastward propagation of the MJO except for CAM4_2d. However, the simulated propagations 

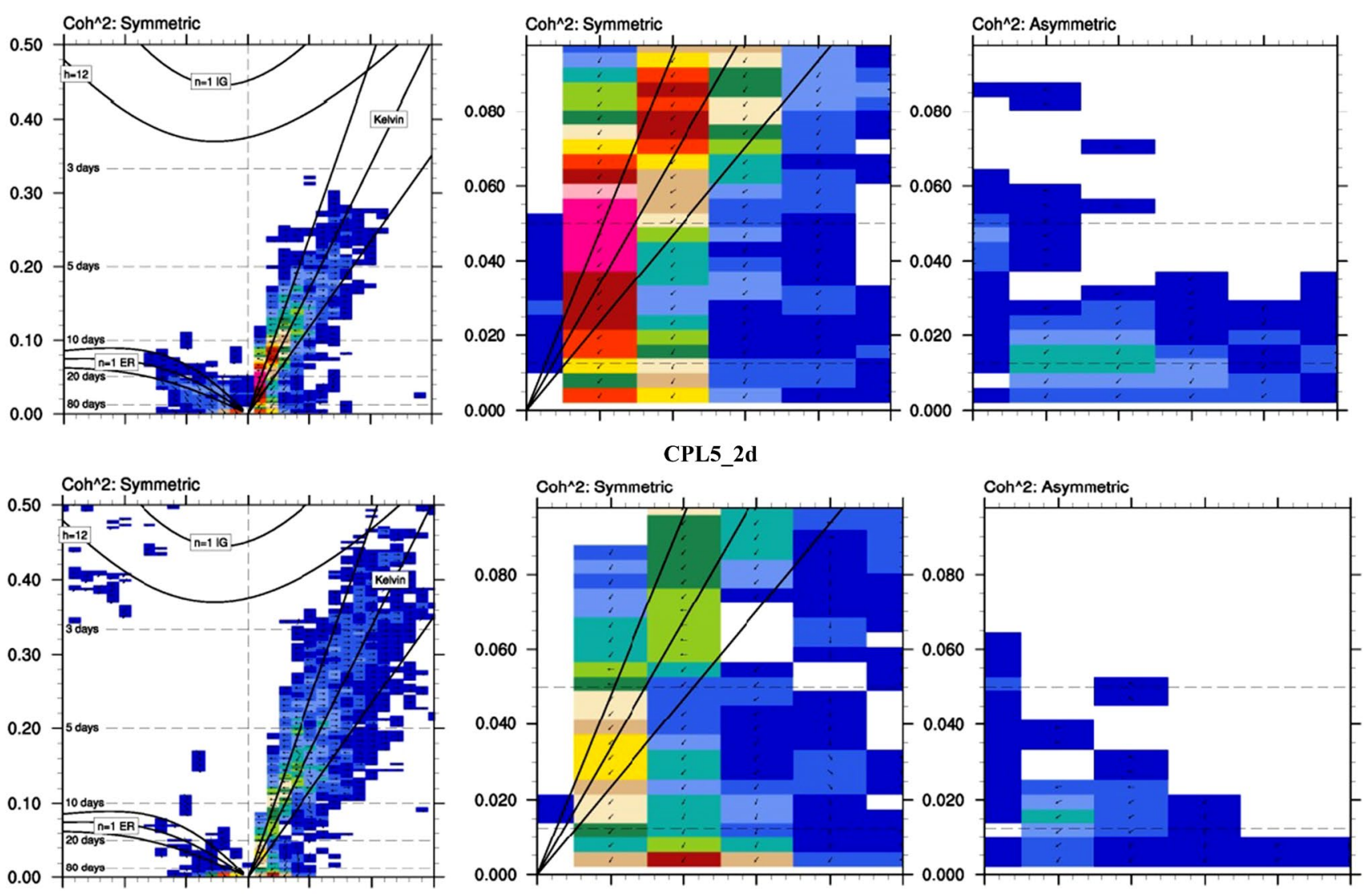

CPL5_1d
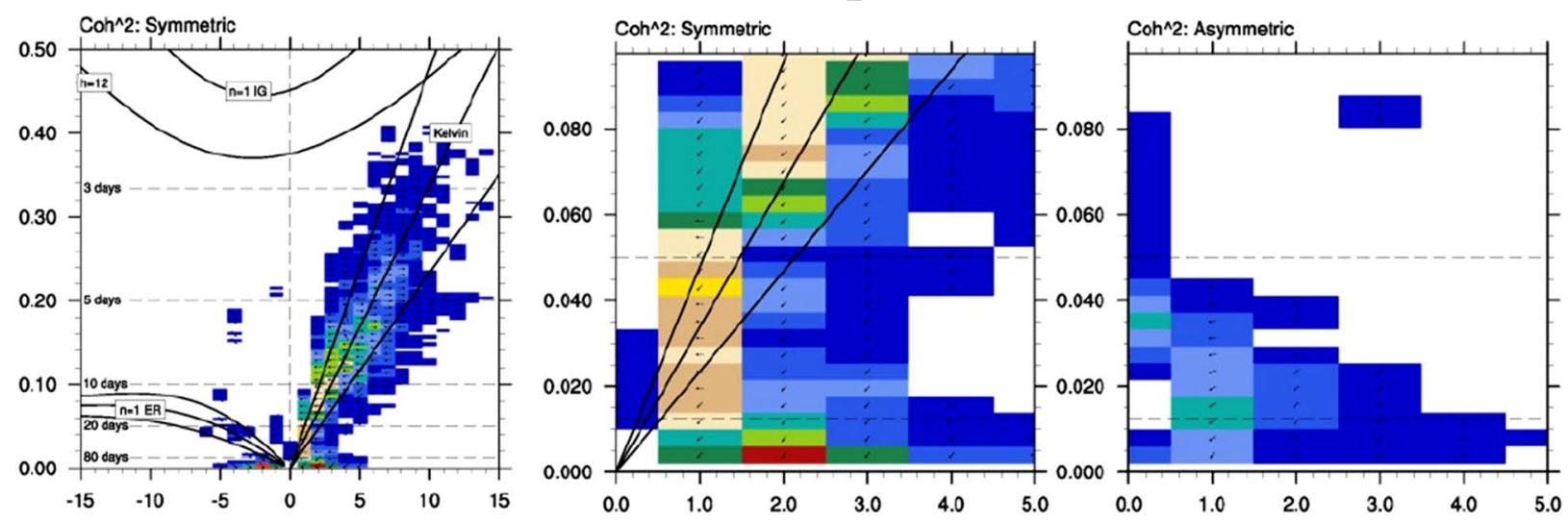

$\begin{array}{lllllll}0.05 & 0.15 & 0.25 & 0.35 & 0.45 & 0.55 & 0.65\end{array}$

Fig. 7 continued

are less coherent and dominant than that in the observations. Among these experiments, CPL5 seems to be more realistic than CAM4 and CPL4, and experiments with $1^{\circ}$ resolution also show better results than those with $2^{\circ}$ resolution, indicating that CAM5 atmosphere physics and high model resolution improve the eastward propagation feature of the MJO simulation.
3.2.2.2 Multivariate combined EOF analysis A multivariate EOF technique, combining OLR, U850 and U200 fields, is also often used to extract MJO mode (e.g., Wheeler and Hendon 2004; Waliser et al. 2009). Different from the univariate EOF analysis, the multivariate EOF can characterize not only the MJO features of the chosen variables but also their coherence at MJO band, which can, for example, 
Fig. 8 The first two EOF modes of AVHRR OLR in the boreal winter. A band-pass filter of 20-100 days is applied prior to EOF analysis. Shown in the upper-right corner is the variance explained by the EOF mode

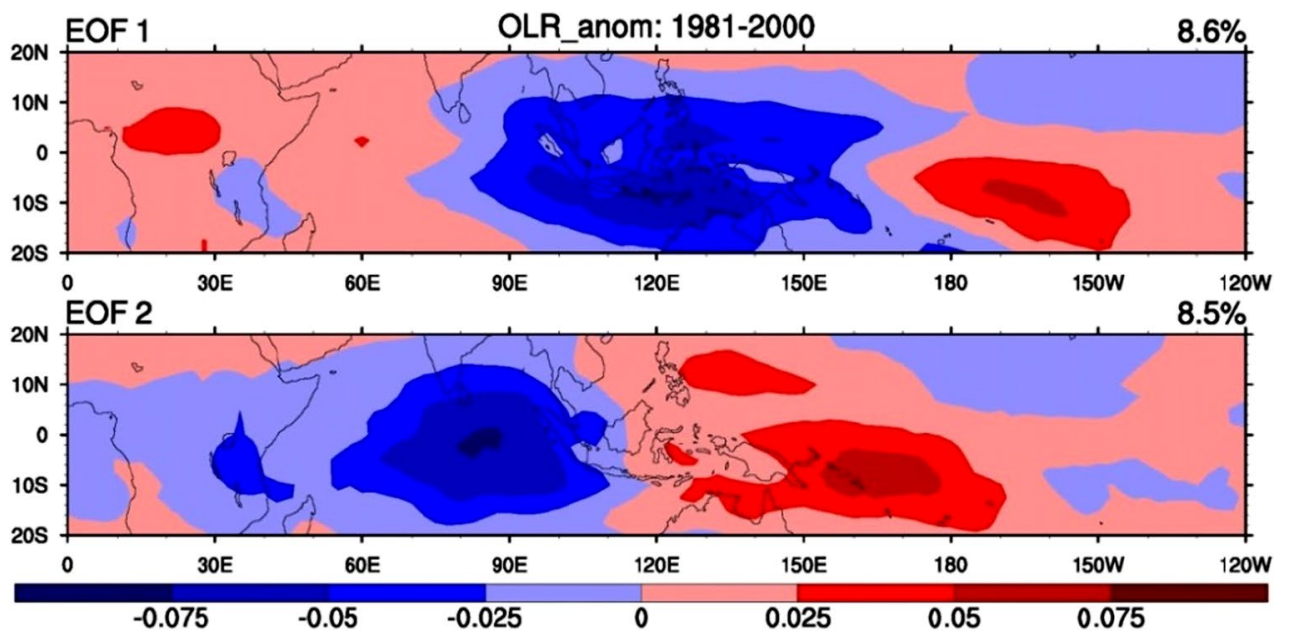

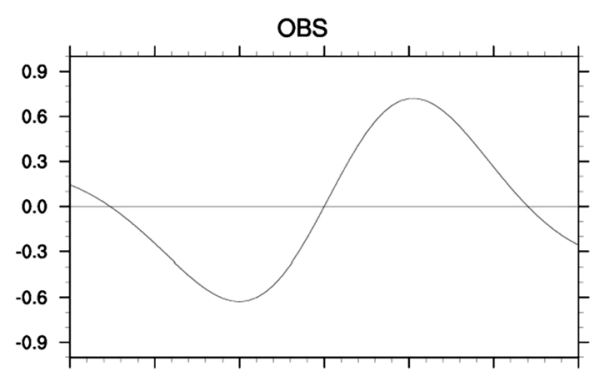
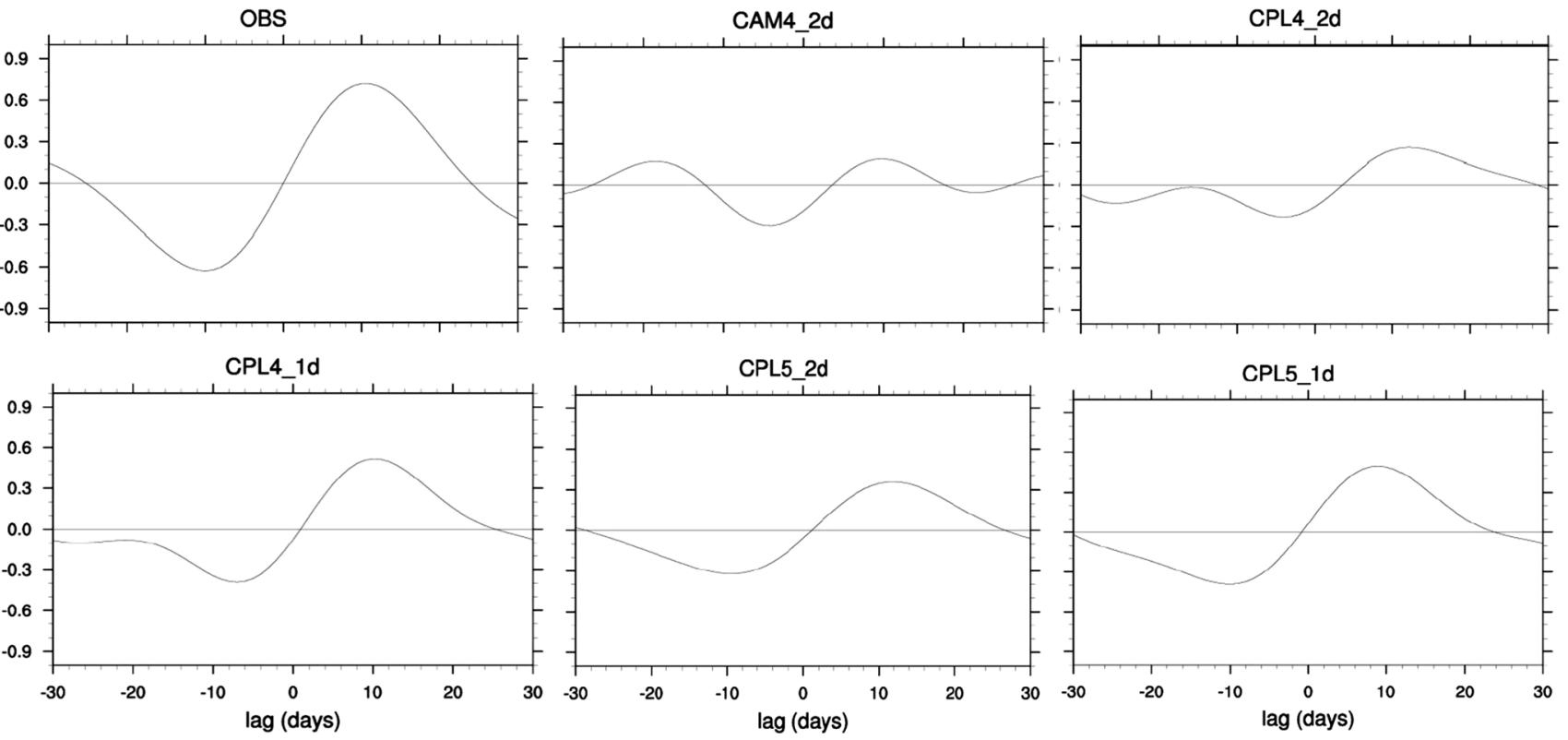

Fig. 9 Time lead-lag correlation of PC1 versus PC2 for all boreal winters (November-April). Positive time lag indicates PC2 leading $\mathrm{PC} 1$, and vice versa. The PCs are obtained by projecting 20-100 day

isolates the convective and baroclinic zonal-wind signatures of the MJO.

MJO mode The first two EOFs from observations and the experiments are shown in Fig. 10. A 20-100 day bandpass filter is used prior to EOFs. The variance explained by each EOF mode is presented in the upper-left corner of each panel. Shown in the upper-right corner of each panel is the variance explained by each variable in the EOF mode. The spatial correlation of model EOF mode against the observed mode is also calculated to measure the model's capability in describing realistic MJO mode.

In the observations, the first EOF mode captures the enhanced (suppressed) convection over the western/central band-pass-filtered daily model OLR onto the two leading EOFs of observed data as shown in Fig. 8

Pacific Ocean and the suppressed (enhanced) convection over the Indian Ocean, while the second EOF mode captures the enhanced (suppressed) convective activity over the eastern Indian Ocean and the Maritime Continent. These two modes constitute the eastward propagation of the MJO, explaining more than $41 \%$ of the total variance; the convection amplitude is concentrated in the EH. Also, it shows an out-of-phase structure between the upper- and lower-troposphere zonal winds, suggesting the baroclinic structure of the MJO, where U200 and U850 inverse at the longitude of $90^{\circ} \mathrm{E}$ for EOF1 and at $150^{\circ} \mathrm{E}$ for EOF2. Besides, there is also a displacement of the zonal wind peak relative to the convection signal with lower-level westerlies tending to trail the convective peak. 
Fig. 10 Multivariate of the first two EOF modes of 20-100-day OLR, 850- and 200-hPa zonal wind averaged over $15^{\circ} \mathrm{N}-15^{\circ} \mathrm{N}$ from every 20 -year experiment run. The total variance accounted for by each mode is written on the left above each panel, and the value on the right above each panel is the variance explained by each individual field. The spatial correlation of model multivariate EOF mode against the observed mode is shown in the middle above each left panel
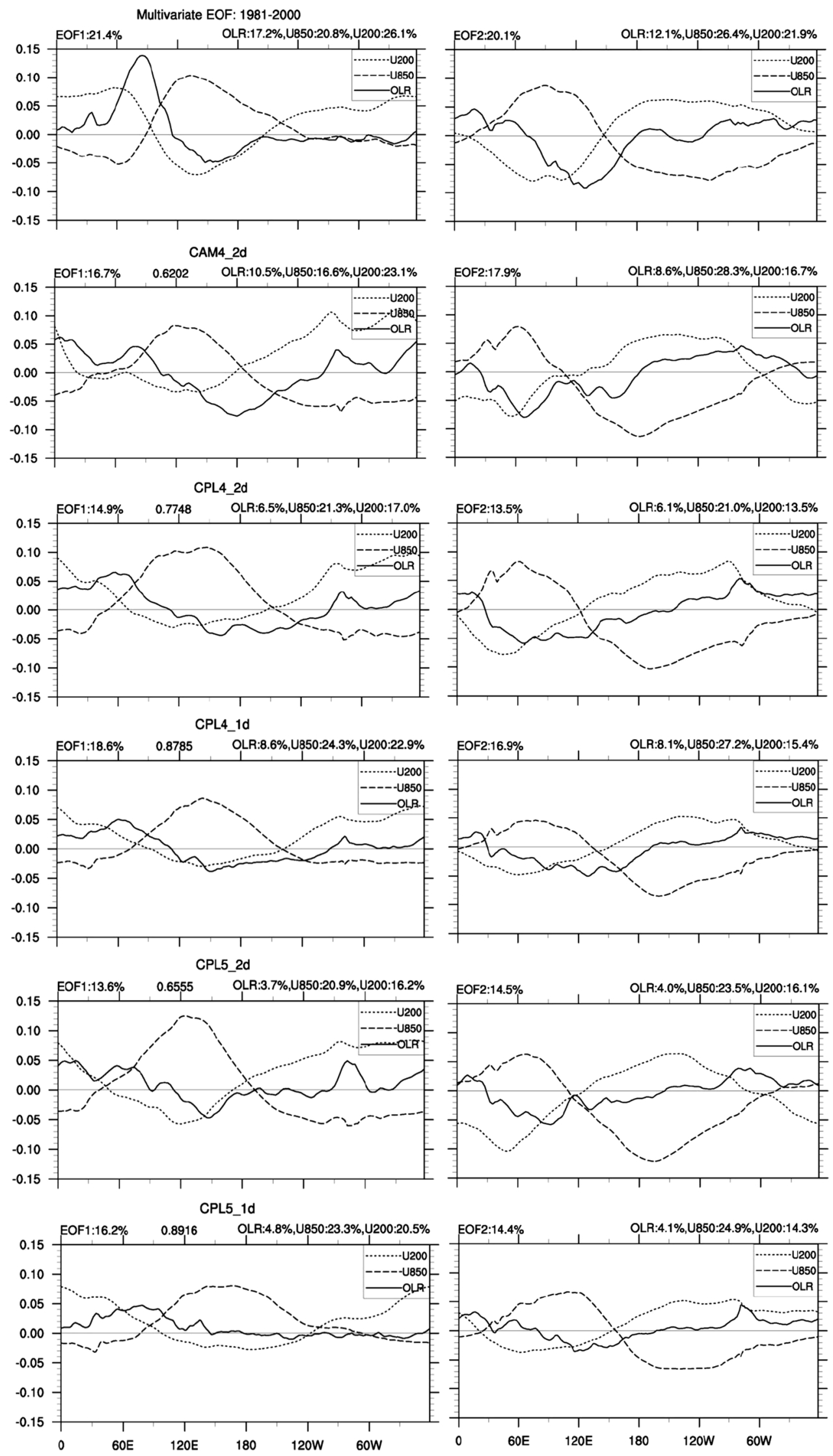

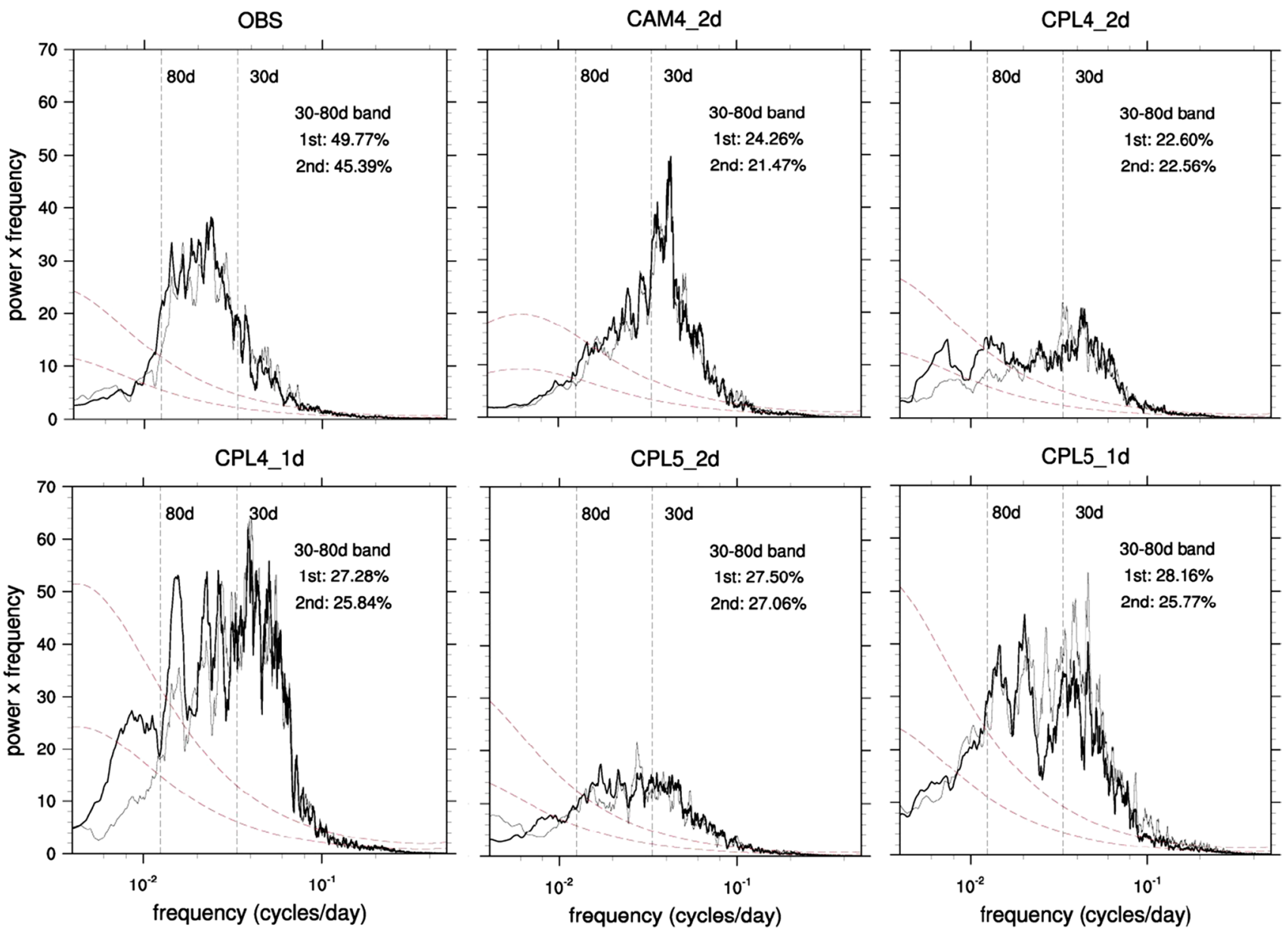

Fig. 11 Power spectra of unfiltered PC1 (thick) and PC2 (thin) that were derived by projecting unfiltered data (seasonal cycle removed) on the observed multivariate EOF1 and EOF2 as shown in Fig. 10.

Dashed curves show the $95 \%$ confidence levels for a red noise spectrum. The numbers shown on the right in each panel are the percentage of 30-80-day period band power with respect to the total power

For convenience of comparison, the first two EOF modes of some model experiments are reordered to match the EOF modes of the observations (e.g., CAM4_2d). The variance explained by each mode in all experiments is smaller than the observed. Especially, the variance of OLR explained by the first two leading modes is much smaller than the observed. Moreover, all experiments display the out-of-phase relationship between lower- and upper-troposphere winds as observed. For CAM4_2d, the pattern correlation of its EOF1 and EOF2 against the observation is about 0.6 with some obvious biases of the anomaly center in the convection and wind fields. The peak positions of the lower- and upper-troposphere winds in EOF1 appear around $130^{\circ} \mathrm{E}$, almost consistent with the observation, but the peaks in EOF2 are located in the western Indian Ocean around $60^{\circ} \mathrm{E}$, which is far away from the observed location around $90^{\circ} \mathrm{E}$. For OLR, the displacement of the peak position exists in both EOF1 and EOF2, indicating biases existed in the eastward and westward propagations. For
CPL4_2d, the pattern correlation is around 0.8, and there are also some improvements compared to CAM4_2d in convection over the western Pacific Ocean in EOF1 and over the Maritime Continent in EOF2, although the variance explained by each mode reduces a little. CPL4_1d performs better than CPL4_2d in terms of the anomaly center and variance explained, with a pattern correlation over 0.8 for both EOF1 and EOF2. The EOF1 in CPL5_2d shows that the convection is located at $120^{\circ} \mathrm{E}-180^{\circ}$, consistent with the range in the observation. However, the OLR of CPL5_2d has much smaller variance explained than the observation. In CPL5_1d, the convective activity over the Pacific is not very dominant, which is not realistic.

Power spectra of unfiltered PCs To examine whether the leading EOFs extracted from band-pass-filtered data are physically meaningful, the power spectra of unfiltered PCs are calculated. The unfiltered PCs are obtained by projecting unfiltered data (with only the seasonal cycle removed) onto the leading EOF modes. If the power spectra exhibit 

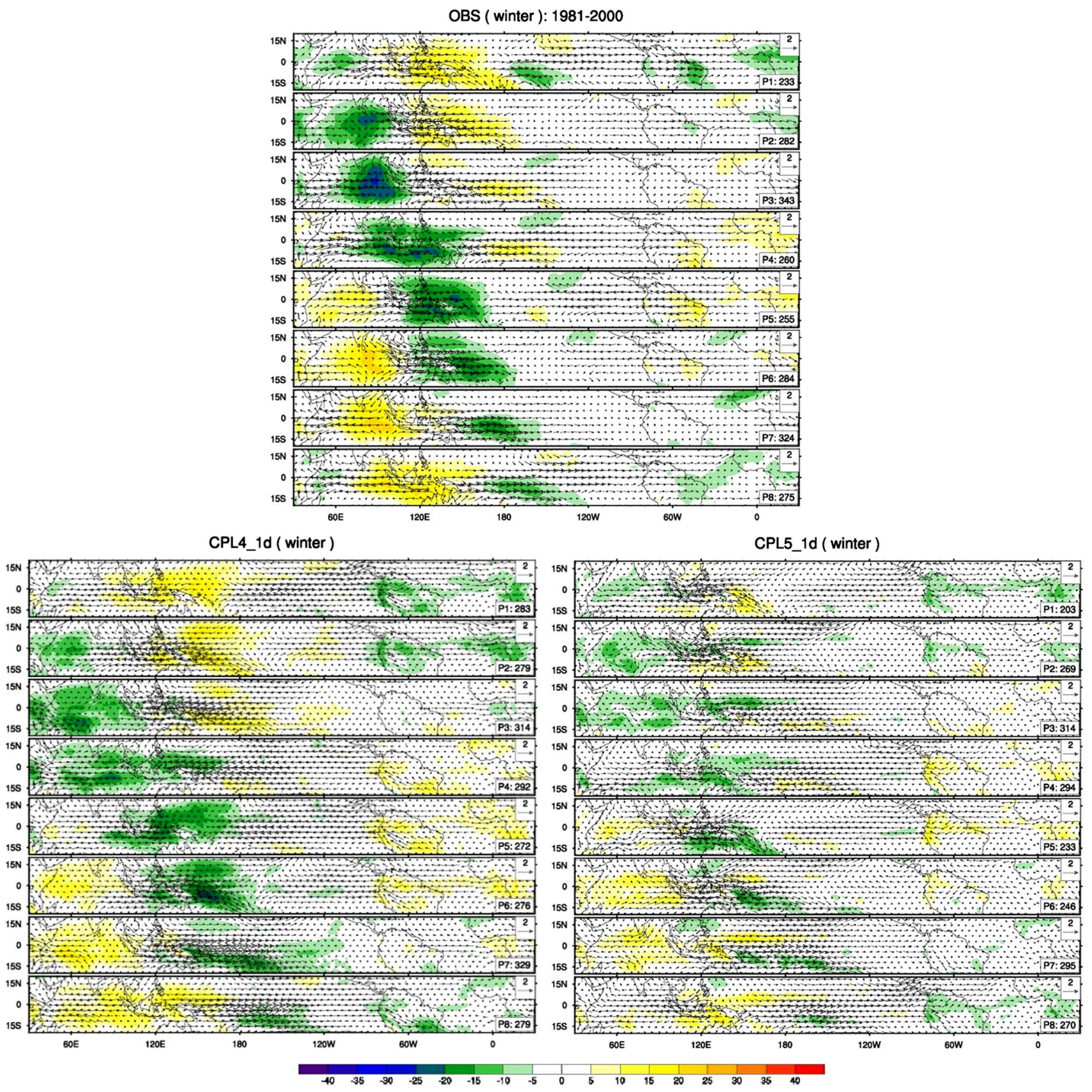

Fig. 12 Composite 20-100-day OLR (shaded) and U850 hPa wind (vector) during the boreal winter as a function of MJO phase. The units of reference vector shown at the top right of each panel are $\mathrm{m} / \mathrm{s}$.

a statistically significant spectral peak at MJO timescale, then we will have confidence that the EOFs represent a meaningful MJO mode.

Figure 11 shows the power spectra. The variance explained by the $30-80$ day period band is computed as well. It can be seen that the observation spectra are concentrated at the periods of 30-80 days for the first two PCs, with variances explained by $\sim 49$ and $\sim 45 \%$. While CAM4_2d has the largest power at periods $<30$ days, the
The number of days used to generate the composite for each phase is shown at the bottom right inside each panel

rest of the coupled experiments have better performances, especially the experiments with $1^{\circ}$ resolution. However, the variance explained at the MJO band is obviously lower in all the models, only taking half of observed variance.

Lag correlation of PCs Here, we use the lag correlations between the PCs of the first two multivariate EOFs to analyze the coherency of convection and wind fields. The results of all experiments indicate that the leading multivariate EOFs are a quadrature pair (not shown), representing coherent 

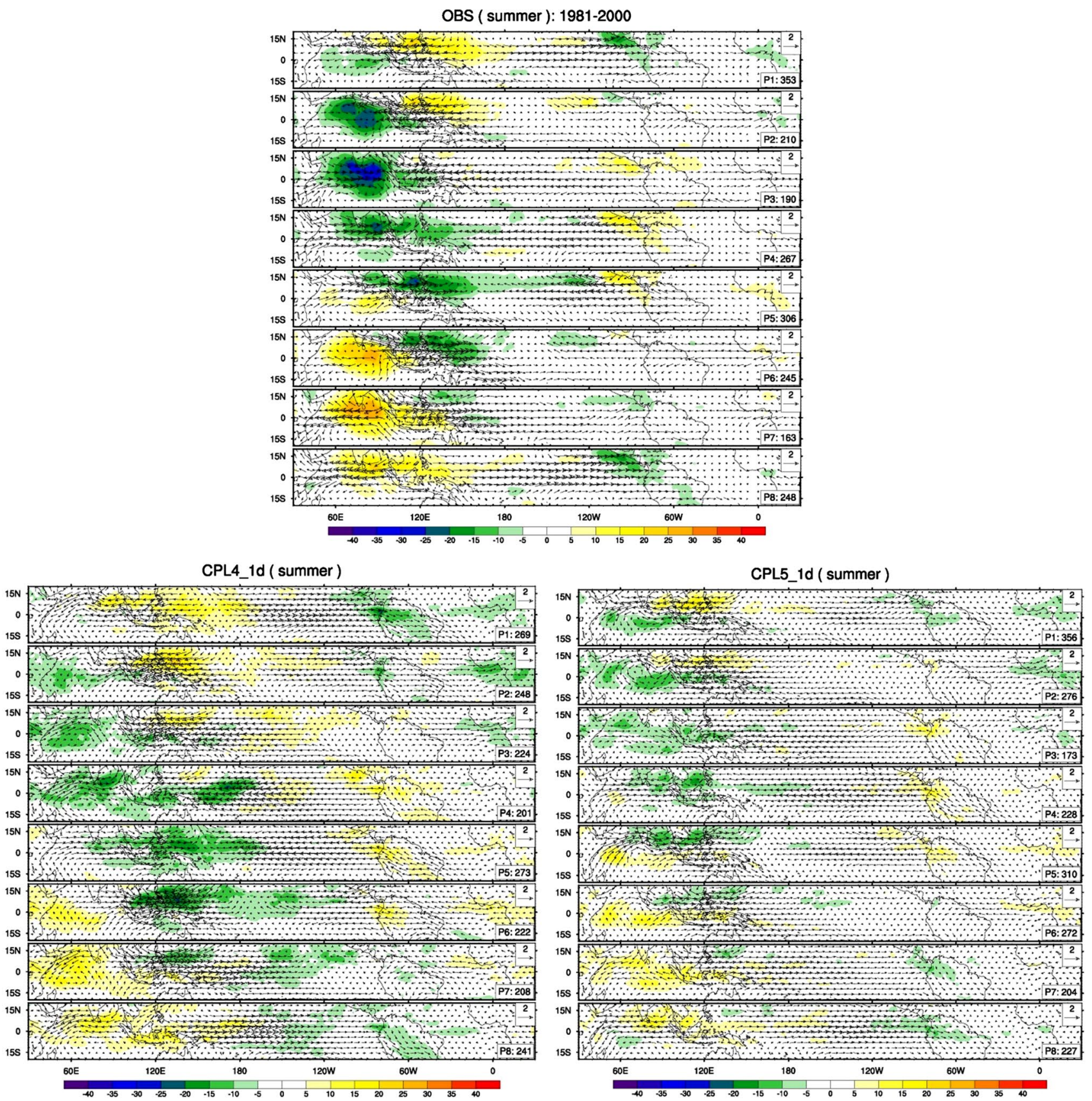

Fig. 13 Same as Fig. 12, except during the boreal summer

eastward-propagating ISV in convection and winds along the equator. The periods in all these experiments are around 36 days, close to the $\sim 40$ days in the observations, which seem better than some models reported in literature (e.g., Lin et al. 2006).

\subsection{Composite of MJO life cycle}

Finally, to examine the model's capability in simulating the spatial-temporal structure of ISV visually, we use the two leading EOFs shown in Fig. 10 to construct a composite
MJO life cycle for the boreal winter and boreal summer, as in Wheeler and Hendon (2004). Only the days with $\mathrm{PC}^{2}+\mathrm{PC}^{2}$ exceeding 1 are used in the composite analysis. Figures 12 and 13 shows the composite maps for the boreal winter and boreal summer, respectively. Considering the coupled models with high resolution have relatively better MJO features than uncoupled and coarse resolution models, we only present the composites for observation, CPL4_1d and CPL5_1d here.

Observations show that the convection is originated in the western Indian Ocean and enhanced to reach its 

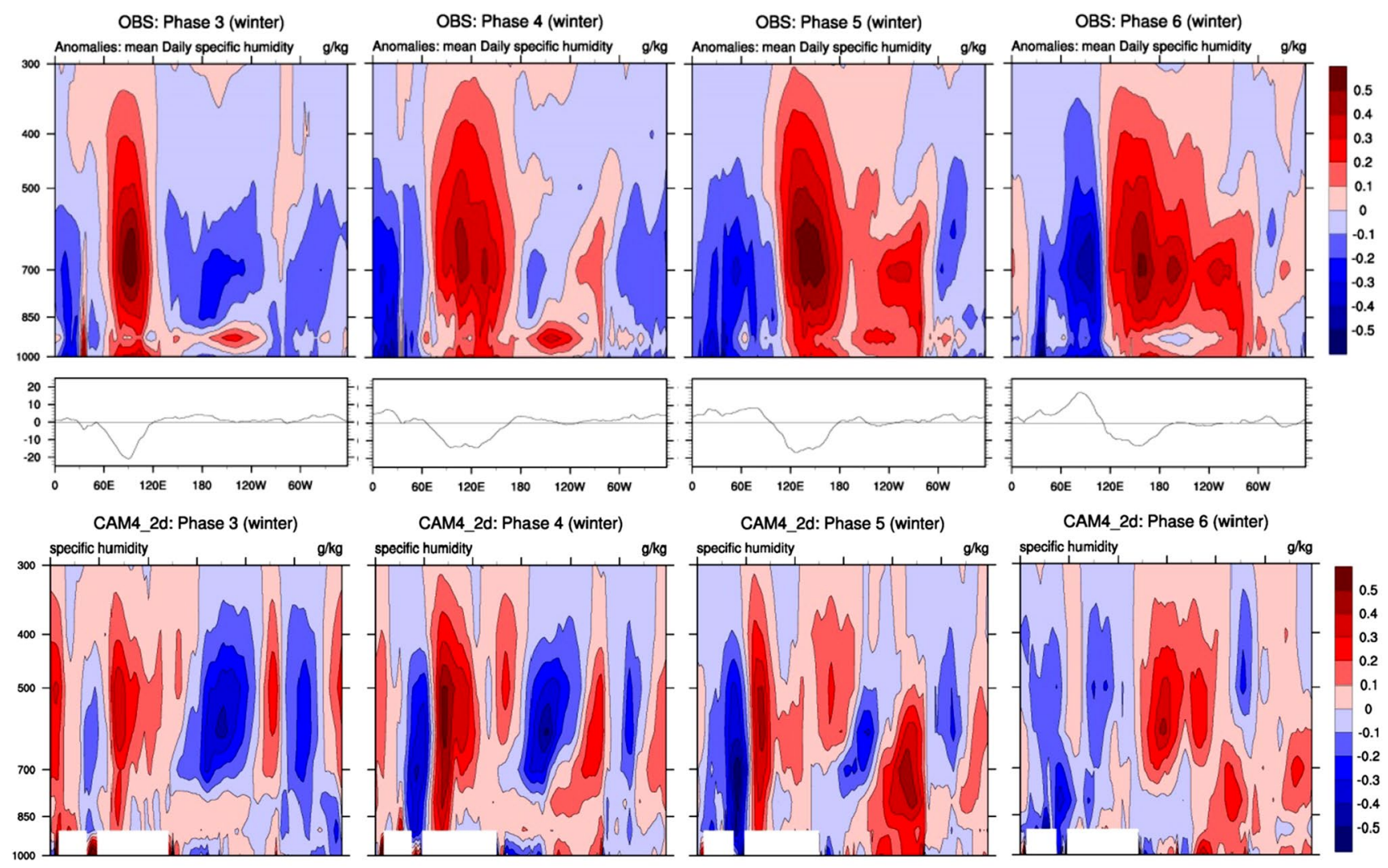

CAM4_2d: Phase 5 (winter)

CAM4_2d: Phase 6 (winter)
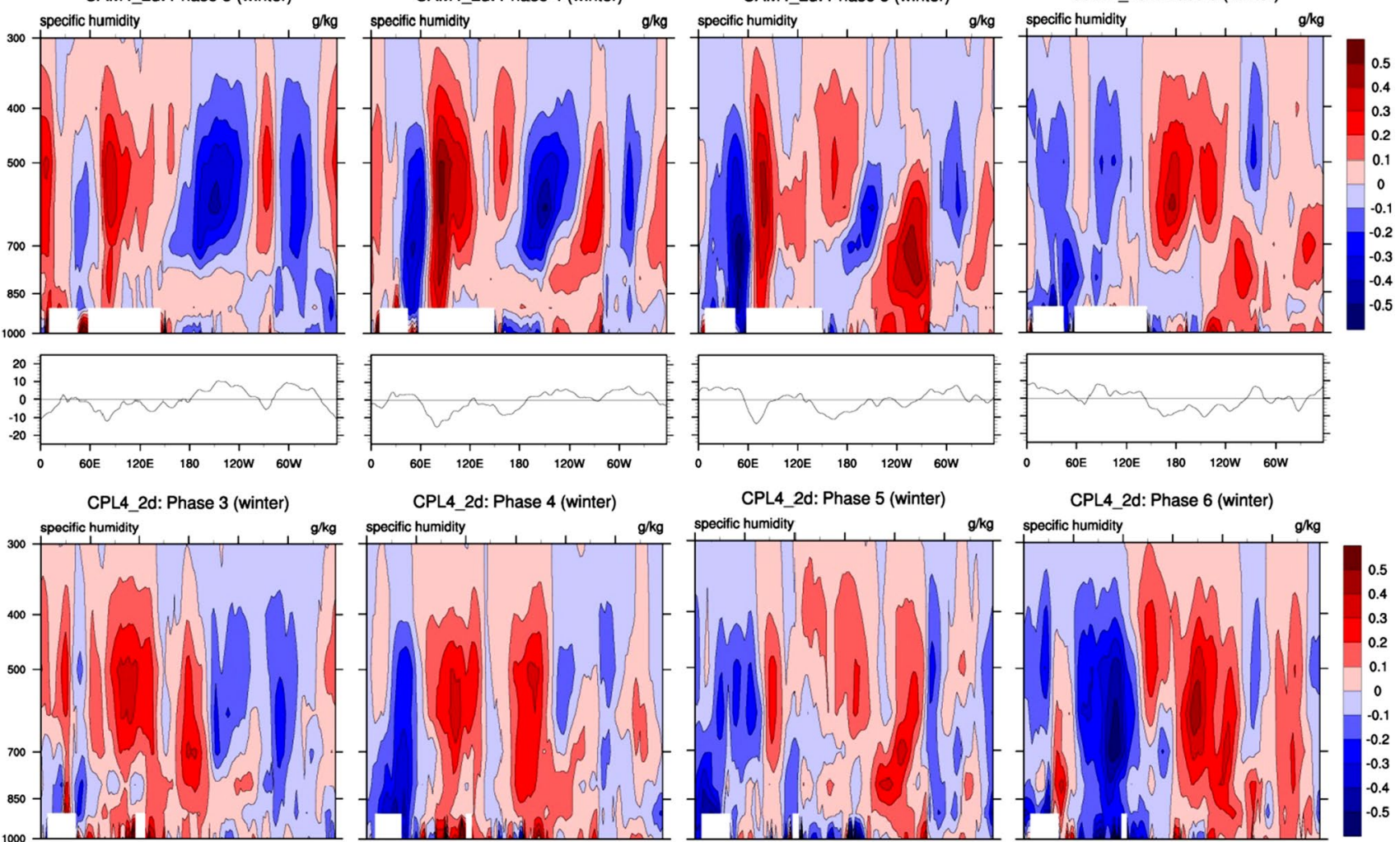

CPL4_2d: Phase 5 (winter)
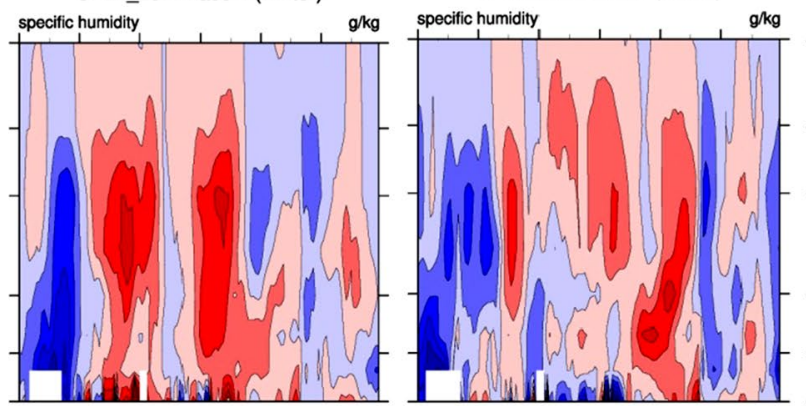

CPL4_2d: Phase 6 (winter)
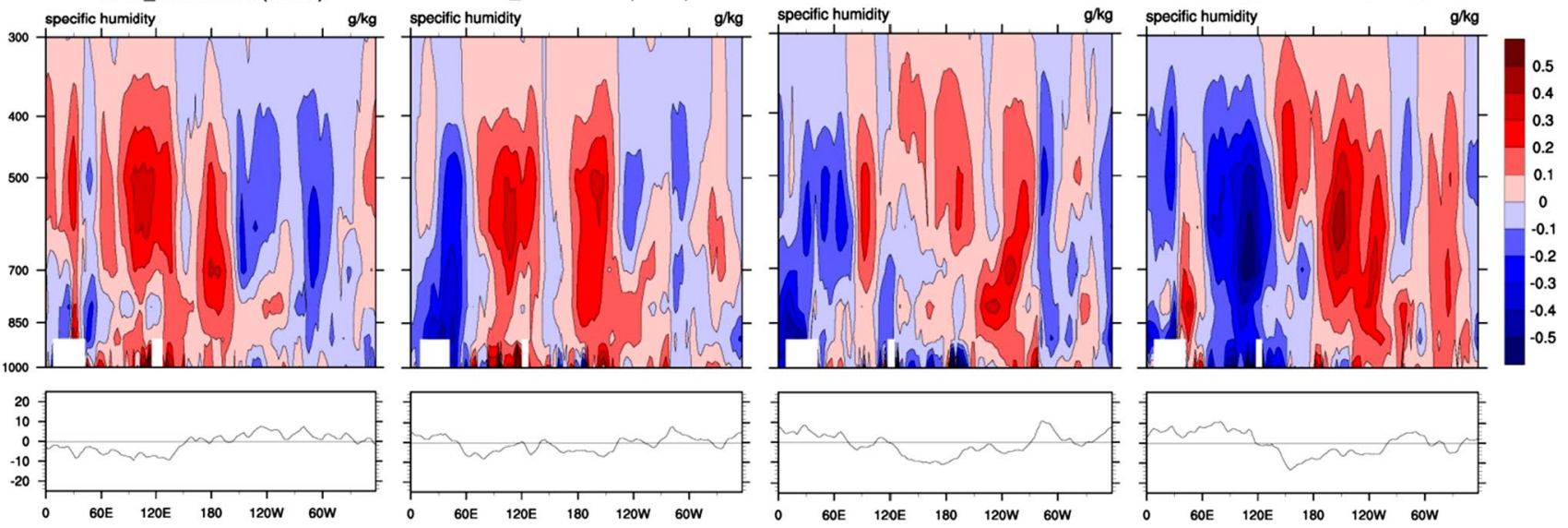

Fig. 14 Pressure-longitude cross section of specific humidity anomalies at the four phases of MJO from five experiments. The OLR anomaly line below each cross section plot shows the location of convection

maximum over the Maritime Continent as it propagates eastward. Then, its strength gradually weakens during further eastward propagation. CPL4_1d shows obvious eastward propagation but there are some biases in terms of detail, such as the faster propagation speed and the broader area with enhanced convection. CPL5_1d shows a more realistic speed of the eastward propagation, but the strength is much weaker than observed, especially in the Indian Ocean. The weak amplitude of the convection strength in CPL5_1d is consistent with the analysis 

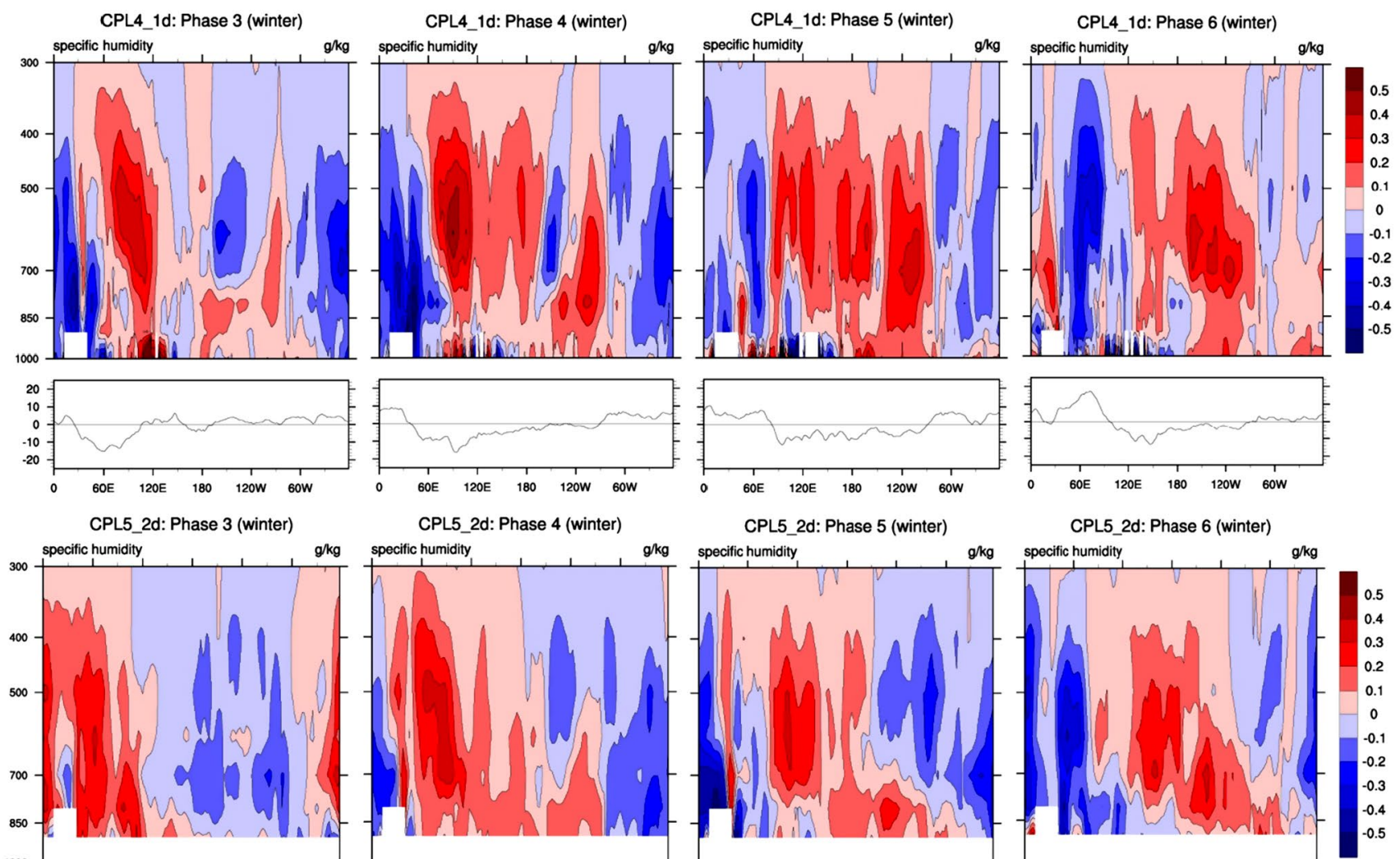

CPL5_2d: Phase 4 (winter)

CPL5 2d: Phase 5 (winter)
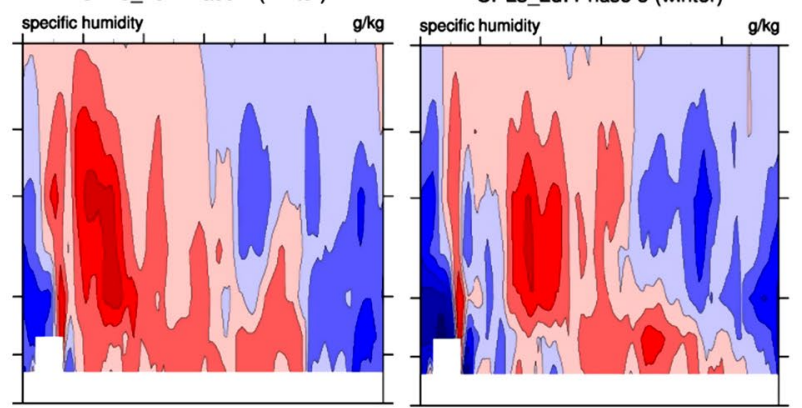

CPL5_2d: Phase 6 (winter)
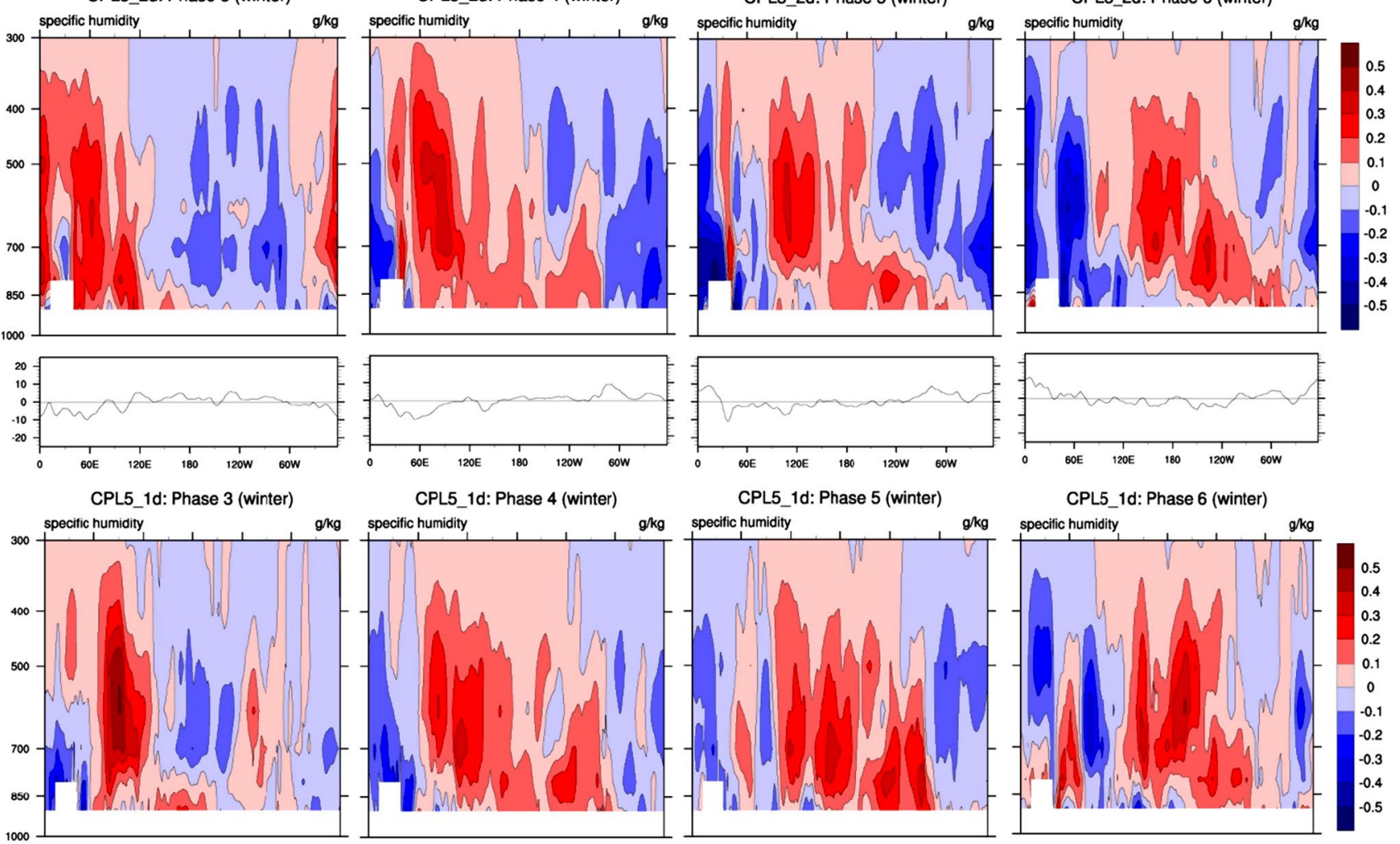

\section{CPL5_1d: Phase 6 (winter)}
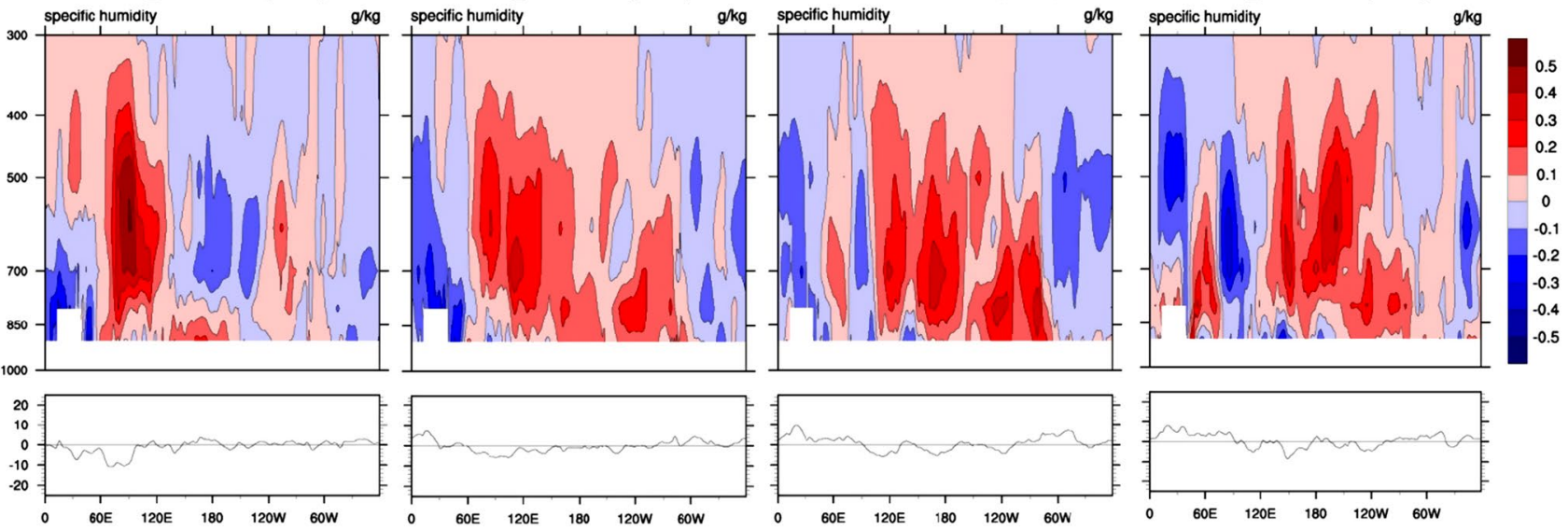

Fig. 14 continued

conducted in proceeding sections, which is probably one main spurious feature in CPL5 experiments. This suggests that the CAM5 has a weaker convection activity than its predecessor.

The eastward propagating activity of MJO in the boreal summer is not as strong as that in the boreal winter in both observation and models. In addition, the observations also show distinct northward propagating convection and winds from the tropical Indian Ocean to the north of the Maritime Continent region, consistent with the results in Sect. 3.1.3. Both CPL4_1d and CPL5_1d display some northward propagation signals. Especially, CPL5_1d is more realistic although its simulated convection strength of the MJO is still weak. 


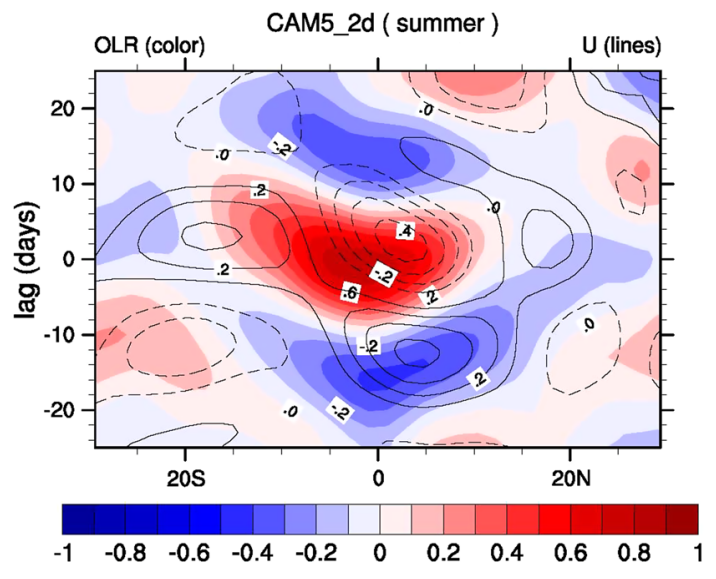

Fig. 15 Similar to Fig. 6, except for the uncoupled experiment with CAM5 atmosphere physics

\subsection{Impact of moisture process on the propagation of MJO}

Shallow convection is considered to be a precondition of the deep convection of lower troposphere in observations (e.g., Kikuchi and Takayabu 2004) and some models (e.g., Kang et al. 2013; Zhang and Song 2009). To further investigate the impact of shallow convection on the MJO features, we analyze the moisture process in observation and in the models in this subsection.

Figure 14 shows the composite $\mathrm{SH}$ anomalies, along the pressure-longitude cross section averaged over $15^{\circ} \mathrm{S}-15^{\circ} \mathrm{N}$ in the phases 3-6 of MJO cycle, for observations and five model experiments, respectively. The corresponding composite OLR anomalies are also shown with respect to the MJO phases. Phase 3 represents the beginning of MJO in the Indian Ocean, while phases 4 and 5 are the processes of MJO crossing the Maritime Continent, and the MJO is matured at phase 6 . For the observations, there are strong positive $\mathrm{SH}$ anomalies in the deep convection region indicated by the negative OLR anomalies. To the east of this region, there is a suppressed deep convection region with positive $\mathrm{SH}$ anomalies in the lower troposphere. With the MJO development, this suppressed region is replaced by a deep convection gradually. The shallow convection transports moisture upward to the mid troposphere, leading to the development of the deep convection. CAM4 shows less coherent moistening process. It should be noticed that the positive $\mathrm{SH}$ anomalies in the Indian Ocean around $90^{\circ} \mathrm{E}$ show a standing mode instead of transiting to negative anomalies with the development of MJO. This may explain why the eastward propagation characteristic is not represented in CAM4 (Fig. 5). As for the other coupled experiments, the experiments with CAM5 atmosphere physics which has a new shallow convection scheme show distinct improvement of the moisture process even with the coarse resolution, although the strength of the $\mathrm{SH}$ anomalies is a little weaker than the observations. This may be the reason of the realistic eastward propagation speed of the CPL5 experiments. The new shallow convection scheme is helpful to the MJO eastward propagation with more realistic process of lower-level convection activity ahead of the deep convection.

What's more, it seems that CPL5 experiments show much more dominant northward propagation characteristic either than uncoupled experiment or than CPL4 experiments (see Fig. 6). In order to distinguish whether the coupling or atmospheric physics plays a curial role to this feature, we run another uncoupled experiment CAM5_2d with CAM5 atmosphere physics and $1.9^{\circ} \times 2.5^{\circ}$ horizontal resolution. The results of lag-longitude analysis, similar to Sect. 3.1.3, are shown in Fig. 15. Comparison between Figs. 15 and 6 reveals that the both OLR and U850 have better northward propagation in CAM5 than in CAM4. Thus, one may conclude that CAM5 physics also improve the northward propagation of MJO simulation. However, a better performance of CMT parameterization is also considered to be important in simulating the northward propagation, which is likely to produce a low-level convergence to the north of the convection (Kang et al. 2010) and unstable planetary waves (Zhou and Kang 2013). Since the sub-grid CMT is introduced to the deep convection schemes in both CAM4 and CAM5, there may be other important processes that contribute to the northward propagation. Figure 16 shows the composite $\mathrm{SH}$ anomalies of pressure-latitude cross section averaged over $90^{\circ} \mathrm{E}-160^{\circ} \mathrm{E}$. Here we only present the observation, CPL4_1d and CPL5_1d, since other models show less realistic moistening process as presented above. Obviously the $\mathrm{SH}$ anomalies proceed northward from the equator at phase 3 to about $15^{\circ} \mathrm{N}$ at phase 6 in the observations, but there is no shallow convection region ahead of the deep convection region which is an obvious feature for the eastward propagation as discussed above. This may suggest different mechanisms responsible for the MJO eastward and northward propagation. In CPL4_1d, the positive SH anomalies are parted in the equator because of the unrealistic negative $\mathrm{SH}$ anomalies in the lower troposphere. The moisture processes in the lower troposphere in CPL5_1d present more resemblance to the observation, although the anomalies are a little weaker, which probably results from the new shallow convection scheme in CAM5. Thus, the realistic representation of the shallow convection is also probably an important factor of the MJO northward propagation.

\section{Summary and discussion}

In this paper, we explore the capability of the latest version of CESM in MJO simulation, and the impacts of air-sea 

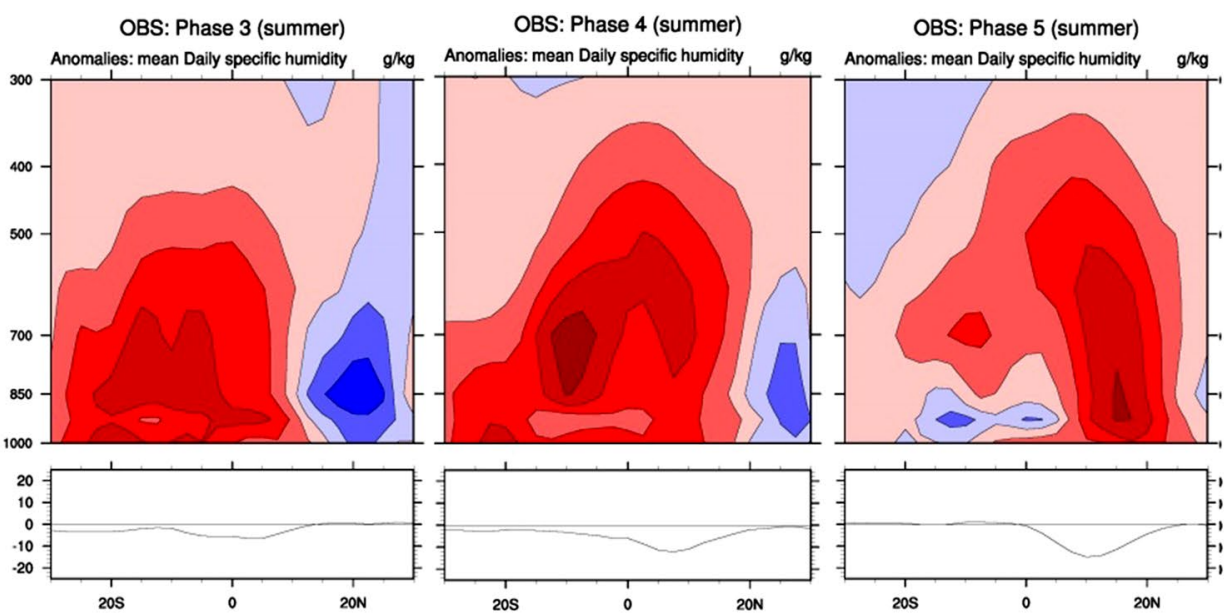

OBS: Phase 6 (summer)

CPL4_1d: Phase 3 (summer)

CPL4_1d: Phase 4 (summer)

CPL4_1d: Phase 5 (summer)
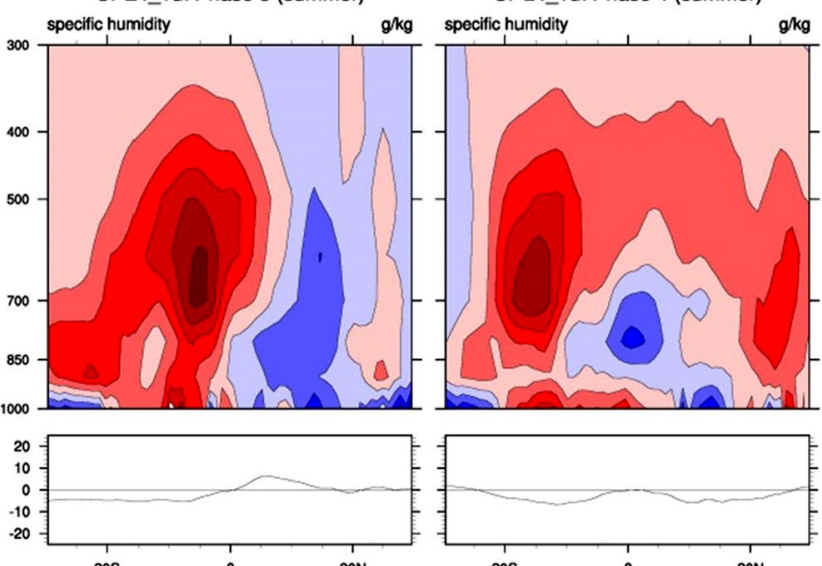

cific humidity

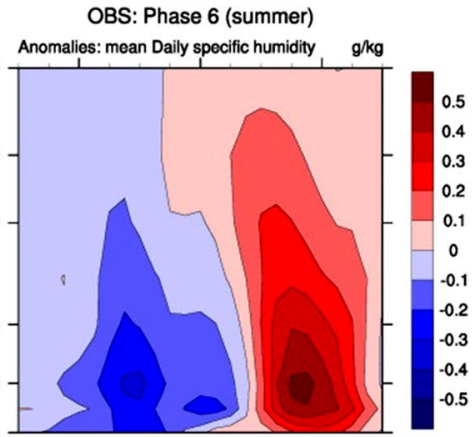

CPL5 1d: Phase 4 (summer)

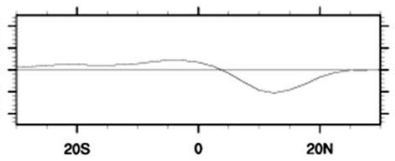

CPL4_1d: Phase 6 (summer)
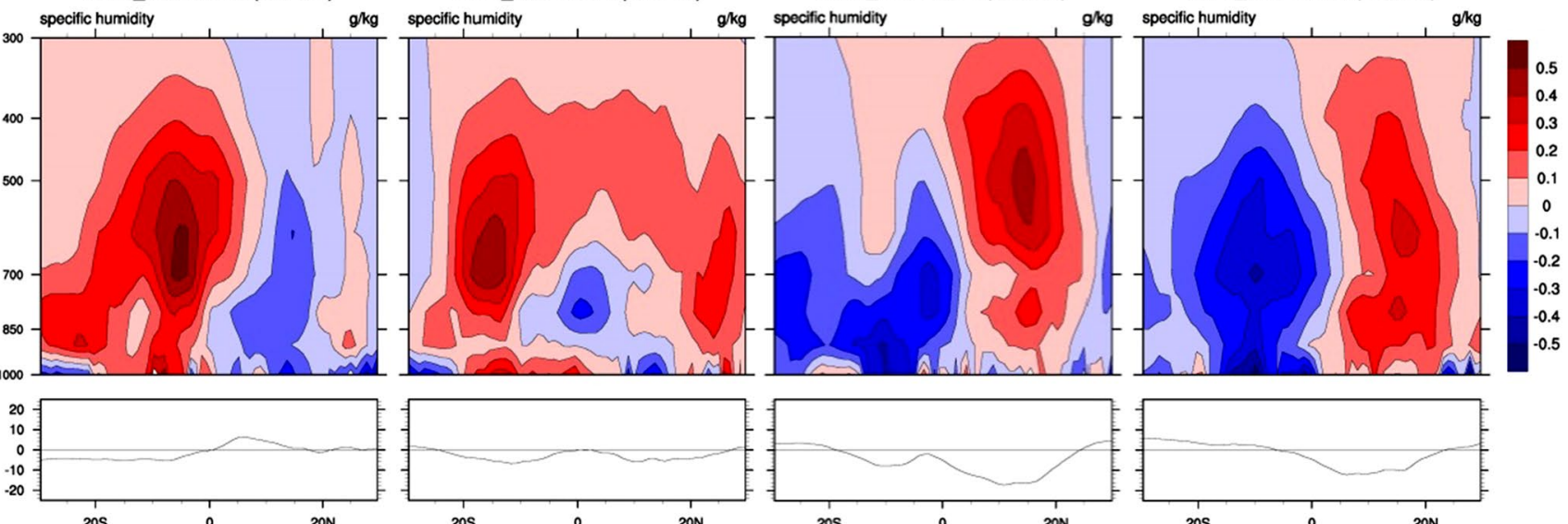

CPL5_1d: Phase 3 (summer)
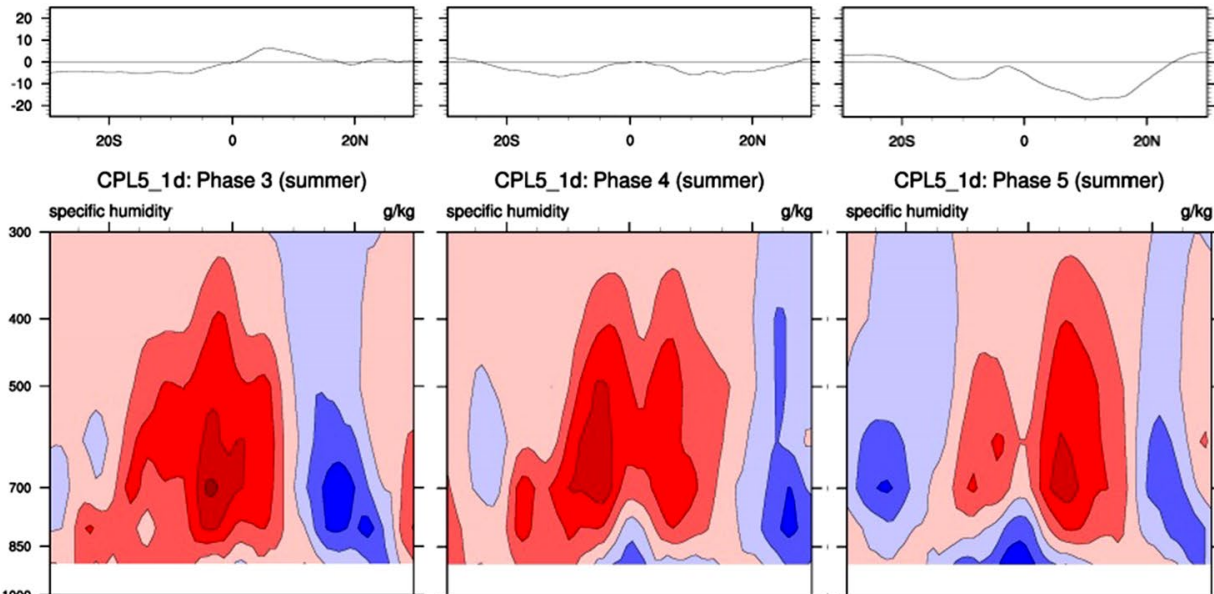

CPL5_1d: Phase 5 (summer)

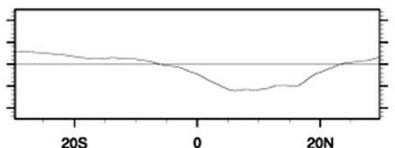

CPL5_1d: Phase 6 (summer)

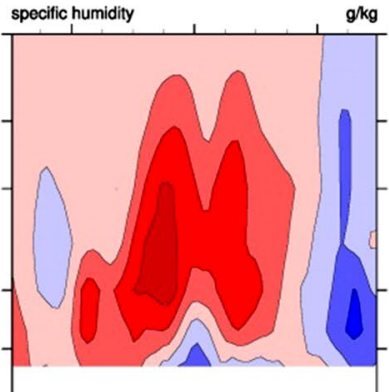

specific humidity specific humidity g/kg
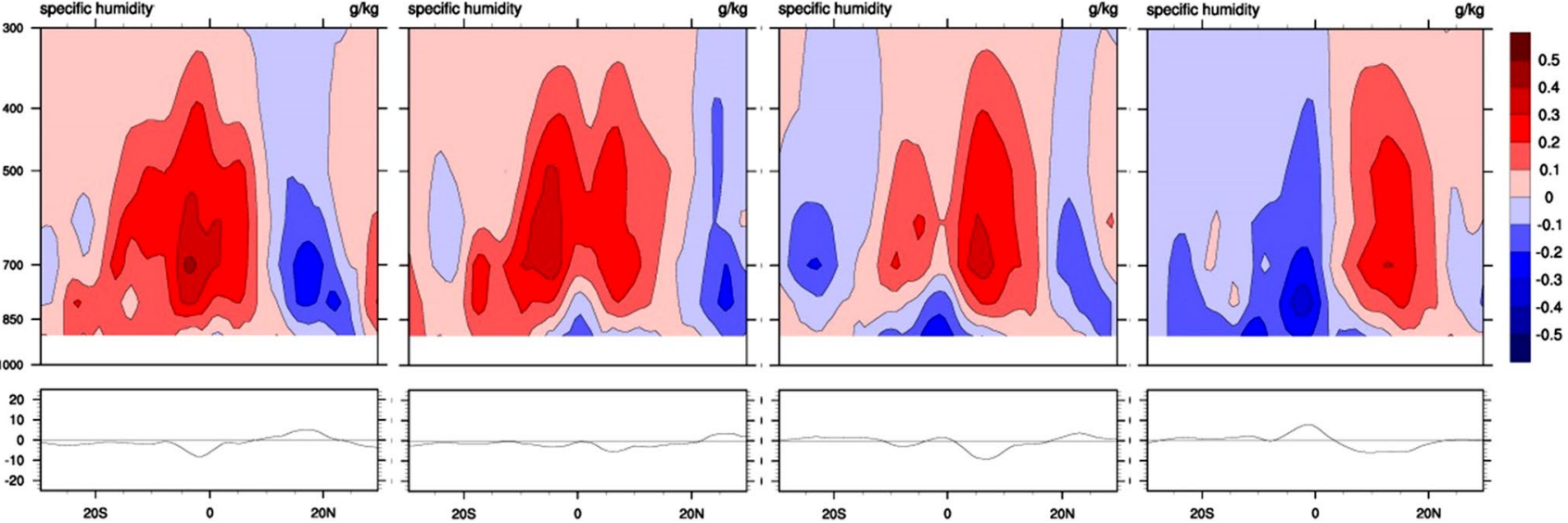

Fig. 16 Same as Fig. 14 except for the pressure-latitude cross section of specific humidity anomalies

coupling, model resolution and different atmospheric physics on MJO simulation by sensitivity experiments.

The effect of air-sea coupling on the MJO simulation is examined by comparing the coupled experiment CPL4_2d and the uncoupled experiment CAM4_2d. To investigate the impact of model horizontal resolution, another coupled experiment with a higher horizontal resolution CPL4_1d is also performed. Meanwhile, as the new version of CESM introduces the updated atmospheric physics CAM5, two different resolution experiments using CAM5 physics are conducted to examine the impacts of different atmospheric physics on MJO simulation. The main results are summarized as follows.

The uncoupled experiment has lower fidelity than the coupled experiments in almost all MJO characteristics 
simulation, including the basic temporal and spatial ISV characteristics and the eastward propagation. For exam$\mathrm{ple}$, the $\mathrm{R}$ value, an indicator of the eastward propagation, of the uncoupled experiment is only one-third of the observed value, while $\mathrm{R}$ in the coupled experiments increases to about half to two-third of the observed value. Also, with ocean feedback, the air-sea interaction improves the coherence of convection and large-scale circulation.

The higher resolution seems to be helpful for a realistic MJO simulation such as the basic ISV spatial distribution and propagation features for both CPL4 and CPL5 experiments. A higher horizontal resolution may be able to resolve the orography, especially the Maritime Continent region, and thus better simulate the basic characteristics related to MJO (e.g., Inness and Slingo 2006). However, it should be noted that the wavenumber-frequency analysis results with two higher resolution models (CPL4 and CPL5) in our experiments indicates that resolution is not a vital factor for realistically reproducing MJO features in wavenumber-frequency spectra.

The CAM4 and CAM5, two different atmospheric physics, have comparable capability in simulating some MJO characteristics such as the ISV spatial distribution and the eastward propagation. The distinct differences occur in the propagation features and the frequencywavenumber analysis of OLR. The new shallow convection scheme in CAM5 physics improves the moisture process of the lower troposphere which is considered as a crucial factor of MJO eastward propagation. So that the eastward propagation speed in the boreal winter for CPL5 shows a resemblance to the observations. In addition, CPL5 also show better northward propagation in the boreal summer than CPL4 due to the realistic shallow convection representation, although the mechanism of northward propagation may be different from that of eastward propagation. On the other hand, the strength of CPL5's convective MJO signal is much weaker than observations, which seems to be the largest deficiency of CPL5 experiments.

MJO simulation has been a challenging issue and attracting a broad attention in recent years. This work presents our recent efforts to investigate some possible factors impacting MJO simulation by the sensitive experiments of CESM, which serves as a necessary step to improve MJO simulation next step. The MJO mechanism and dynamic processes responsible its basic features are still not clear although there are considerable hypotheses. Thus, for simplicity and brevity, we confine in this work our discussions mostly in the analyses and comparisons of the experiments themselves, with light weights on the dynamical mechanisms. More sensitivity experiments and comprehensive diagnostic analyses are needed to understand the dominant physical and dynamical processes of the MJO, which may be pursued in the near future.

Acknowledgments This work was supported by the National Science Foundation of China (41276029, 41321004, 41530961, 91528304), National Programme on Global Change and Air-Sea Interaction (GASI-IPOVAI-04, GASI-IPOVAI-06), the National Basic Research Program (2013CB430302), the NSERC (Natural Sciences and Engineering Research Council of Canada) Discovery Grant, the scientific research fund of the Second Institute of Oceanography of China (14202), the Predictability of Ocean Dynamical System Project (151053), and the project of State Key Laboratory of Satellite Ocean Environment Dynamics (SOEDZZ1404, SOEDZZ1518).

Open Access This article is distributed under the terms of the Creative Commons Attribution 4.0 International License (http://creativecommons.org/licenses/by/4.0/), which permits unrestricted use, distribution, and reproduction in any medium, provided you give appropriate credit to the original author(s) and the source, provide a link to the Creative Commons license, and indicate if changes were made.

\section{References}

Bai XX, Li CY, Tan YK, Guan ZJ (2013) The impacts of MaddenJulian oscillation on spring rainfall in East China. J Trop Meteorol 19:214-222

Boyle JS, Klein SA, Lucas DD, Ma HY, Tannahill J, Xie S (2015) The parametric sensitivity of CAM5's MJO. J Geophys Res 120:2014JD022507. doi:10.1002/2014JD022507

Cai Q, Zhang GJ, Zhou T (2013) Impacts of shallow convection on MJO simulation: a moist static energy and moisture budget analysis. J Clim 26(8):2417-2431

Crueger T, Stevens B, Brokopf R (2013) The Madden-Julian oscillation in ECHAM6 and the introduction of an objective MJO metric. J Clim 26:3241-3257

Ding RQ, Li JP, Seo KH (2010) Predictability of the Madden-Julian oscillation estimated using observational data. Mon Weather Rev 138:1004-1013

Duchon CE (1979) Lanczos filtering in one and two dimensions. J Appl Meteorol 18:1016-1022

Easter RC et al (2004) MIRAGE: model description and evaluation of aerosols and trace gases. J Geophys Res 109:D20210. doi:10.10 29/2004JD004571

Evans S, Marchand R, Ackerman T (2014) Variability of the Australian monsoon and precipitation trends at Darwin. J Clim 27:8487-8500

Gettelman A, Liu X, Ghan SJ, Morrison H, Park S, Conley AJ, Klein SA, Boyle J, Mitchell DL, Li J-LF (2010) Global simulations of ice nucleation and ice supersaturation with an improved cloud scheme in the community atmosphere model. J Geophys Res 115:D18216. doi:10.1029/2009JD013797

Hendon HH, Wheeler MC (2008) Some space-time spectral analyses of tropical convection and planetary-scale waves. J Atmos Sci 65(9):2936-2948

Hoell A, Barlow M, Wheeler MC, Funk C (2014) Disruptions of El Nino-Southern Oscillation teleconnections by the MaddenJulian oscillation. Geophys Res Lett 41:998-1004

Hurrell JW, Hack JJ, Shea D, Caron JM, Rosinski J (2008) A new sea surface temperature and sea ice boundary dataset for the community atmosphere model. J Clim 21:5145-5153

Iacono MJ, Delamere JS, Mlawer EJ, Shephard MW, Clough SA, Collins WD (2008) Radiative forcing by long-lived greenhouse 
gases: calculations with the AER radiative transfer models. J Geophys Res 113:D13103. doi:10.1029/2008JD009944

Inness PM, Slingo JM (2006) The interaction of the Madden-Julian oscillation with the maritime continent in a GCM. Q J R Meteorol Soc 132:1645-1667. doi:10.1256/qj.05.102

Kalnay E, Kanamitsu M, Kistler R, Collins W, Deaven D, Gandin L, Iredell M, Saha S, White G, Woollen J, Zhu Y, Leetmaa A, Reynolds R, Chelliah M, Ebisuzaki W, Higgins W, Janowiak J, Mo KC, Ropelewski C, Wang J, Jenne R, Joseph D (1996) The NCEP/NCAR 40-year reanalysis project. Bull Am Meteorol Soc 77:437-470

Kanamitsu M, Ebisuzaki W, Woollen J, Yang S-K, Hnilo J, Fiorino M, Potter G (2002) NCEP-DOE AMIP-II reanalysis (R-2). Bull Am Meteorol Soc 83:1631-1643

Kang I-S, Kim H-M (2010) Assessment of MJO predictability for boreal winter with various statistical and dynamical models. J Clim 23:2368-2378

Kang I-S, Kim D, Kug J-S (2010) Mechanism for northward propagation of boreal summer intraseasonal oscillation: convective momentum transport. Geophys Res Lett 37:L24804. doi:10.102 9/2010g1045072

Kang I-S, Liu F, Ahn M-S, Yang Y-M, Wang B (2013) Role of SST structure on convectively coupled Kelvin-Rossby waves and its implication on MJO formation. J Clim 26:5915-5930

Kang I-S, Jang P-H, Almazroui M (2014) Examination of multi-perturbation methods for ensemble prediction of the MJO during boreal summer. Clim Dyn 42:2627-2637

Kemball-Cook S, Wang B (2001) Equatorial waves and air-sea interaction in the Boreal summer intraseasonal oscillation. J Clim 14:2923-2942

Kikuchi K, Takayabu YN (2004) The development of organized convection associated with the MJO during TOGA COARE IOP: trimodal characteristics. Geophys Res Lett 31:L10101. doi:10.102 9/2004GL019601

Kiladis GN, Wheeler MC, Haertel PT, Straub KH, Roundy PE (2009) Convectively coupled equatorial waves. Rev Geophys 47:RG2003. doi:10.1029/2008RG000266

Kim D, Sperber K, Stern W, Waliser D, Kang I-S, Maloney E, Wang W, Weickmann K, Benedict J, Khairoutdinov M, Lee M-I, Neale R, Suarez M, Thayer-Calder K, Zhang G (2009) Application of MJO simulation diagnostics to climate models. J Clim 22:6413-6436

Li T (2014) Recent advance in understanding the dynamics of the Madden-Julian oscillation. J Meteorol Res 28:1-33

Liebmann B, Smith CA (1996) Description of a complete (interpolated) outgoing longwave radiation dataset. Bull Am Meteorol Soc 77:1275-1277

Lin JL, Kiladis GN, Mapes BE, Weickmann KM, Sperber KR, Lin W, Wheeler MC, Schubert SD, Genio AD, Donner LJ, Emori S, Gueremy J-F, Hourdin F, Rasch PJ, Roeckner E, Scinocca JF (2006) Tropical intraseasonal variability in 14 IPCC AR4 climate models. Part I: convective signals. J Clim 19:2665-2690

Lin H, Brunet G, Mo RP (2010) Impact of the Madden-Julian oscillation on wintertime precipitation in Canada. Mon Weather Rev 138:3822-3839

Liu X, Easter RC, Ghan SJ, Zaveri R, Rasch P, Shi X, Lamarque J-F, Gettelman A, Morrison H, Vitt F, Conley A, Park S, Neale R, Hannay C, Ekman AML, Hess P, Mahowald N, Collins W, Iacono MJ, Bretherton CS, Flanner MG, Mitchell D (2012) Toward a minimal representation of aerosols in climate models: description and evaluation in the community atmosphere model CAM5. Geosci Model Dev 5:709-739. doi:10.5194/gmd-5-709-2012

Madden RA, Julian PR (1994) Observations of the 40-50-day tropical oscillation-a review. Mon Weather Rev 122:814-837

Moon J, Wang B, Kwon WT (2007) The response of northern hemisphere atmospheric circulation to the northward migration of tropical forcing. J Korean Meteorol Soc 43:253-265
Morrison H, Gettelman A (2008) A new two-moment bulk stratiform cloud microphysics scheme in the community atmosphere model, version 3 (CAM3). Part I: description and numerical tests. J Clim 21:3642-3659

Mu M, Zhang GJ (2008) Energetics of Madden-Julian oscillations in the NCAR CAM3: a composite view. J Geophys Res 113:D05108. doi:10.1029/2007JD008700

Neale RB, Richter JH, Jochum M (2008) The impact of convection on ENSO: from a delayed oscillator to a series of events. J Clim 21:5904-5924

Neale RB, Gettelman A, Park S, Conley AJ, Kinnison D, Marsh D, Smith AK, Vitt F Morrison H, Cameron-Smith P, Collins WD, Iacono MJ, Easter RC, Liu X, Taylor MA (2010a) Description of the NCAR community atmosphere model (CAM 5.0). NCAR technical note no. NCAR/TN-486+ STR, National Center for Atmospheric Research, Boulder

Neale RB, Richter JH, Conley AJ, Park S, Lauritzen PH, Gettelman A, Williamson DL, Rasch PJ, Vavrus SJ, Taylor MA, Collins WD, Zhang M, Lin S-J (2010b) Description of the NCAR community atmosphere model (CAM 4.0). NCAR technical note no. NCAR/TN-485 + STR, National Center for Atmospheric Research, Boulder

Park S, Bretherton CS (2009) The University of Washington shallow convection and moist turbulence schemes and their impact on climate simulations with the community atmosphere model. J Clim 22:3449-3469

Roundy PE (2008) Analysis of convectively coupled Kelvin waves in the Indian ocean MJO. J Atmos Sci 65:1342-1359

Roundy PE, Kravitz JR (2009) The association of the evolution of intraseasonal oscillations to ENSO phase. J Clim 22:381-395

Sharmila S, Pillai PA, Joseph S, Roxy M, Krishna RPM, Chattopadhyay R, Abhilash S, Sahai AK, Goswami BN (2013) Role of ocean-atmosphere interaction on northward propagation of Indian summer monsoon intra-seasonal oscillations (MISO). Clim Dyn 41:1651-1669. doi:10.1007/s00382-013-1854-1

Shelly A, Xavier P, Copsey D, Johns T, Rodriguez JM, Milton S, Klingaman N (2014) Coupled versus uncoupled hindcast simulations of the Madden-Julian oscillation in the year of tropical convection. Geophys Res Lett 41:5670-5677

Sperber KR (2004) Madden-Julian variability in NCAR CAM2.0 and CCSM2.0. Clim Dyn 23:259-278

Sperber KR, Kim D (2012) Simplified metrics for the identification of the Madden-Julian oscillation in models. Atmos Sci Lett 13:187-193

Subramanian AC, Jochum M, Miller AJ, Murtugudde R, Neale RB, Waliser DE (2011) The Madden-Julian oscillation in CCSM4. J Clim 24:6261-6282

Tang YM, Yu B (2008a) MJO and its relationship to ENSO. J Geophys Res 113:D14106. doi:10.1029/2007JD009230

Tang YM, Yu B (2008b) An analysis of nonlinear relationship between the MJO and ENSO. J Meteorol Soc Jpn 86:867-881

Waliser D, Sperber K, Hendon H, Kim D, Maloney E, Wheeler M, Weickmann K, Zhang C, Donner L, Gottschalck J, Higgins W, Kang I-S, Legler D, Moncrieff M, Schubert S, Stern W, Vitart F, Wang B, Wang W, Woolnough S (2009) MJO simulation diagnostics. J Clim 22:3006-3030

Wang B, Rui H (1990) Dynamics of the coupled moist KelvinRossby wave on an equatorial $\beta$-plane. J Atmos Sci 47:397-413

Wang WQ, Hung MP, Weaver SJ, Kumar A, Fu XH (2014) MJO prediction in the NCEP climate forecast system version 2. Clim Dyn 42:2509-2520

Wheeler MC, Hendon HH (2004) An all-season real-time multivariate MJO index: development of an index for monitoring and prediction. Mon Weather Rev 132:1917-1932

Wheeler M, Kiladis GN (1999) Convectively coupled equatorial waves: analysis of clouds and temperature in the wavenumberfrequency domain. J Atmos Sci 56:374-399 
Zhang C (2005) Madden-Julian oscillation. Rev Geophys 43:RG2003. doi:10.1029/2004RG000158

Zhang GJ, Mcfarlane NA (1995) Sensitivity of climate simulations to the parameterization of cumulus convection in the Canadian Climate Center general-circulation model. Atmos Ocean 33:407-446

Zhang GJ, Mu M (2005) Simulation of the Madden-Julian oscillation in the NCAR CCM3 using a revised Zhang-McFarlane convection parameterization scheme. J Clim 18:4046-4064

Zhang GJ, Song X (2009) Interaction of deep and shallow convection is key to Madden-Julian oscillation simulation. Geophys Res Lett 36:L09708. doi:10.1029/2009GL037340
Zhang C, Dong M, Gualdi S, Hendon HH, Maloney ED, Marshall A, Sperber KR, Wang W (2006) Simulations of the Madden-Julian oscillation in four pairs of coupled and uncoupled global models. Clim Dyn 27:573-592

Zhou L, Kang I-S (2013) Influence of convective momentum transport on mixed Rossby-Gravity waves: a contribution to tropical 2-day waves. J Atmos Sci 70:2467-2475. doi:10.1175/ jas-d-12-0300.1 